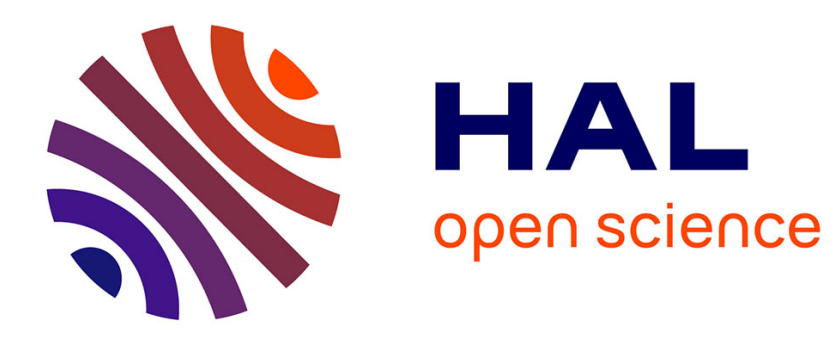

\title{
Dynamics of social norms in the city
}

Fabien Moizeau

\section{To cite this version:}

Fabien Moizeau. Dynamics of social norms in the city. Regional Science and Urban Economics, 2015, 51, pp.70-87. 10.1016/j.regsciurbeco.2015.01.005 . halshs-01114139

\section{HAL Id: halshs-01114139 \\ https://shs.hal.science/halshs-01114139}

Submitted on 11 Apr 2015

HAL is a multi-disciplinary open access archive for the deposit and dissemination of scientific research documents, whether they are published or not. The documents may come from teaching and research institutions in France or abroad, or from public or private research centers.
L'archive ouverte pluridisciplinaire HAL, est destinée au dépôt et à la diffusion de documents scientifiques de niveau recherche, publiés ou non, émanant des établissements d'enseignement et de recherche français ou étrangers, des laboratoires publics ou privés. 


\title{
Dynamics of Social Norms in the City*
}

\author{
Fabien MOIZEAU ${ }^{\dagger}$
}

January 2015

\begin{abstract}
We study how in a city either opposite social norms remain or a particular code of behavior spreads and ultimately prevails. We develop a multicommunity model with overlapping generations. When young, an individual chooses a certain level of educational effort. The crucial feature is that the decision is influenced by peers living in the area who favor a social norm either valuing education or discrediting it. When an adult, an individual who cares about both her offspring's expected income and the social norm chooses the family's location. Endogenous location leads to different patterns of social norms in the city. We identify two types of urban equilibrium: a culturally-balanced city where social norms are distributed evenly among urban areas and where the rate of education is the same in each urban area and a culturally-divided city where urban areas oppose on their prevailing social norm and exhibit different rates of education. We then study the dynamics of social norms. We show that there are multiple long-run patterns of social norms. A particular steady state is achieved depending on the initial distribution support for social norms in the population. Finally, we show that a public policy promoting social integration can lead, in the long run, to a population unanimously discrediting education. Enforcing social integration can obtain less education than allowing the culturally-divided city to arise.
\end{abstract}

Keywords: peer effects, social norms, residential segregation, human capital inequality.

JEL Classification: D31, I24, O40, R23.

\footnotetext{
*I wish to thank the Editor, Yves Zenou, and two anonymous referees for their insightful comments that led to substantial improvements in this article. I am very grateful to Emeline Bezin, Olivier l'Haridon, Gabin Langevin, Benoît Tarroux, Pascaline Vincent for their comments on an earlier version of the paper. I also thank conference participants at PET 14 Seattle and seminar participants at CREM. Financial support from the Agence Nationale de la Recherche (ANR-12-INEG-0002) is gratefully acknowledged.

${ }^{\dagger}$ CREM (Condorcet Center), Université de Rennes 1 and Institut Universitaire de France, email: fabien.moizeau@univ-rennes1.fr.
} 


\section{Introduction}

The striking fact about urban inequality is that social problems such as criminal activities, unemployment, school drop-out rates, teenage childbearing, are concentrated in urban areas, for instance the inner-city areas in the US and the suburbs in Europe. Ethnographic and sociological studies have documented that the concentration of social problems in depressed communities may entertain a culture of poverty which opposes the mainstream culture and traps their inhabitants into poverty (see among others Wilson, 1987, Anderson 1999 and the survey of Lamont and Small, 2008). The concentration of social problems in some depressed communities is thus a threat for social cohesion and raises the issue of the design of public policies aiming to fight against urban inequality.

The purpose of this paper is to understand why, in some urban areas, subcultures favoring standards of behavior which prove to be detrimental for their inhabitants emerge and perpetuate over time. We focus on particular neighborhood effects, that is social norms followed by peers. Youth decisions are driven by the concern to follow some social norms because obedience to the code of behavior prescribed by a particular social norm generates reputation benefits while disobedience incurs stigmatization costs.

There is now a widespread consensus on the influence of social interactions on behavioral and economic outcomes. In particular, the youth while taking decisions appear to be strongly influenced by their local environment. For instance, Gaviria and Raphael (2001) find strong evidence of peer-group effects at the school level for drug use, alcohol drinking, cigarette smoking, church going and the likelihood of dropping out of high school. Furthermore, there is evidence that these peer-group effects may be the result of peer pressure. At school level, it has been widely documented that pupils engage in harassment and other types of peer pressure in order to enforce norms of behavior (see Bishop, 2003, for a broad review of ethnographic and psychological studies on this issue and also for the study he conducted from the Educational Excellence Alliance's Survey of Student Culture) ${ }^{1}$. One explanation of the racial achievement gap in education lies in 'acting white' peer externality which refers to the stigmatization exerted by peers if one invests in the behavioral characteristic of whites (see Fryer and Torelli, 2010). Furthermore, using data from the 'Moving To Opportunity' experiment, Kling et al. (2007) find modest peer effects in education for the male youth. They explain this result by saying that the experimental male group may have

\footnotetext{
${ }^{1}$ Studying peer effects in the workplace, Mas and Moretti (2009) find evidence of the influence of coworkers' productivity on work effort. This influence is stronger for coworkers with whom interactions are frequent, corroborating that social pressure is a way to internalize free-riding externalities.
} 
responded to peer pressure to signal that they have not abandoned their original neighborhood culture by returning to the original neighborhood.

These local interactions may help explain why socioeconomic opportunities vary with the place of residence (see for instance the surveys of Durlauf, 2004, Ioannides, 2013, Topa and Zenou, 2014). The recent work of Chetty et al. (2014) provides new evidence that patterns of social mobility differ significantly across space. Using data from the federal income tax records over the period 1996-2012, they study a measure of absolute upward mobility defined as the mean income rank of children with parents in the bottom half of the income distribution. They divide the US into 741 Commuting Zones. They obtain that for commuting zones in the top decile the income rank is above the $52^{\text {nd }}$ percentile while it is below the $37^{\text {th }}$ percentile in the bottom decile. This difference translates into substantial differences in children's incomes. Furthermore, Chetty et al. (2014) find that upward social mobility is significantly correlated to observable characteristics of commuting zones. In particular, they find a strong negative correlation with segregation by race or income and a positive correlation with quality of the K-12 school system (measured by lower drop-out rates, higher test scores and smaller class sizes). This study stresses that local environment may be key to explain the spatial variation of social mobility although it does not prove any causal relationship. ${ }^{2}$

This paper studies the relationship between dynamics of social norms and urban inequality. In order to grasp both the local nature and the dynamic aspect of a social norm influence, we develop a multicommunity model with overlapping generations. Individuals live two periods, childhood and adulthood. When a child, each individual decides which level of educational effort to exert. In accordance with the empirical results mentioned above on the strong evidence of peer influence at school, we assume that the education decision depends on the economic returns to education, the cost of effort and also the reputation benefits and stigmatization costs generated by the adherence to or the deviation from, respectively, the social norm. We consider that a child faces two opposing social norms: one valuing education and prescribing high effort (named the 'education' social norm) and the other one depreciating schooling effort and prescribing low effort at school (named the 'no education' social norm). We assume that children are heterogeneous with respect to their preferences. Individuals are called education believers or non education believers, respectively, when they take care about the costs and benefits of adhering to or deviating from the 'education'

\footnotetext{
${ }^{2}$ Spatial variation of socioeconomic success is also observed in France. Using data on public middle schools in Paris, Fack and Grenet (2010) find that performance varies significantly across space. Best public middle schools tend to be located in both the central and western parts of Paris while the worst public schools are in the north-eastern district.
} 
or 'no education' social norm. We capture the local nature of a social norm assuming that the stigmatization costs and reputation benefits of a social norm depend on the fraction of inhabitants in the urban area who believe in this social norm. When an adult, an individual chooses the place of residence of the family, comprised of her offspring and herself. In a first step, we assume limited altruism so that parents only care about their child's future income. Hence, the intensity of a social norm is endogenous as it will be determined by the emerging urban equilibrium. The second key feature of the model is that the population of believers in a social norm evolves over time. In this respect, we follow the argument of Akerlof (1980) that a social norm spreads if the number of individuals adhering to the social norm is greater than the number of individuals believing in this social norm. Our model thus allows us to study the interplay between the dynamics of opposite social norms and the dynamics of the organization of the city. At date $t$, a particular urban equilibrium may emerge depending on the population characteristics, that is the number of believers and non-believers in the population. This equilibrium implies particular incentives to educate in each neighborhood. This will drive a new number of believers which gives rise to a new urban configuration at date $t+1$. On the whole, the social norms dynamics are driven by the urban configuration that arises.

Our results are threefold. First, we identify urban equilibria that arise at each date $t$ and that are characterized by the spatial distribution of believers and non-believers. In particular, a symmetric equilibrium, called 'culturally-balanced', emerges where believers and non-believers are uniformly located in the city leading urban areas to be identical with respect to the social norms mix. It turns out that incentives faced by any child to exert educational effort are independent of their location. Education rates are identical across urban areas. On the contrary, some asymmetric equilibria, called 'culturally-divided', can also arise. They are such that urban areas differ with respect to the prevailing social norm and the implied education rate. Depending on the fraction of believers in the whole population, the 'culturally-divided' city can exhibit two types of cultural clash: either an urban area only inhabited by believers that unanimously promotes education and contrasts with other locations where both social norms are present, or an urban area only inhabited by non-believers deterring from any education effort and that opposes other urban areas with both social norms. The asymmetric equilibria are consistent with the significant variation across space of social mobility found by Chetty et al. (2014). Second, we study the social norms dynamics which arise under either cultural division or cultural integration. We show that social norms dynamics exhibit a contagion process so that once the population of believers in the urban area reaches a threshold, the underlying social norm spreads. In particular, if the number of believers 
in the 'education' social norm is too low then the urban area can be trapped in a low-education equilibrium while high education is promoted in the rest of the city. Hence, the initial number of believers is key to determine the type of long-run equilibrium that is reached. This model thus highlights how two societies with slight differences in their populations of believers may exhibit very different social norms dynamics and experience varying performances in terms of education. Third, we show that if the culturally-balanced equilibrium is imposed by the government it may reach a low-level equilibrium at the steady state. On the contrary, this same economy would obtain the culturally-divided equilibrium under laissez-faire and would exhibit dynamics reaching a high-level equilibrium. This result corroborates findings by Cutler, Glaeser and Vigdor (2008) on the positive impact of isolation on better-educated groups.

We then study two extensions of the model. First, we assume that parents are affected by the social norms of the neighborhood. Second, we consider that utility of private consumption is strictly concave. It turns out that the willingness to pay to live in an urban area depends on both social norms effects and income effect. In particular, if their child adheres to the 'no education' social norm, parents are no longer willing to pay to live in the urban area with the strongest incentives for education as her offspring might incur stigmatization by peers. Furthermore, income inequality is also key to determine the highest bidders for a particular urban area. This extended model gives rise to a richer pattern of urban equilibria.

Our paper belongs to three strands of literature. First, it is related to the literature on human capital accumulation with neighborhood effects which has been impulsed by Loury (1977) and Bénabou (1993, 1996a,b). We depart from their work as we focus on particular neighborhood effects, that is social norms, that involve reputation or stigmatization effects which shape incentives to educate and follow the norm. We are thus able to study the dynamics of neighborhood effects and characterize the conditions under which a social norm spreads or, on the contrary, disappears over time. Second, our paper belongs to the economic literature on social norms which has explored how the influence of social norms helps to explain unemployment (see for instance Akerlof, 1980), trade union membership (see Naylor 1989, Corneo, 1995), decisions about work and benefits in the welfare state (see Lindbeck, Nyberg and Weibull, 1999) or more generally the emergence of cooperation (see, for instance, Tabellini, 2008). We depart from this literature as costs and benefits to follow a social norm depend on the neighborhood population characterizing an urban equilibrium. Third, our paper also belongs to the literature on the formation of oppositional identities (see Akerlof and Kranton, 2000, Battu, Mwale and Zenou, 2007, Bisin, Patacchini, Verdier and Zenou, 2011). Compared to this literature, our contribution is that the persistence 
or the disappearance of a particular social norm relies on the endogenous degree of segregation between believers and non-believers.

The plan of the paper is as follows. In the following section we set up the model. In section 3 , we characterize the urban equilibrium which emerges at each date $t$. Then in section 4 , we study the dynamics of social norms when cultural division perpetuates. In section 5 , we examine the influence of cultural balance on the dynamics of social norms and long-run economic performances. In section 6 , we study some extensions of the model. Section 7 concludes.

\section{The Setup}

We consider an overlapping generations model of neighborhood formation. The essential features of the model are such that (i) during their life, individuals make educational decisions and location choices, (ii) and that individuals derive utility from obeying a particular social norm.

\subsection{The City}

The city is comprised of two residential areas indexed by $j=1,2$. We consider that landowners are absent and without loss of generality we normalize the opportunity cost of building a house to 0 . Houses are identical across the city. The inelastic supply of houses within a residential area is of mass $L$. This land market is a closed-city model where the population of the city is a continuum of families of mass $N$. Each family, comprised of a parent and a child, lives in one and only one house. The city can accommodate the entire population and we assume for the sake of simplicity that $L=N / 2$. Agents live two periods. When a child, an individual faces a discrete educational choice. When an adult, an individual has to decide in which neighborhood her family will reside.

\subsection{Children's Educational Choice and Social Norms}

Preferences. Any child $i$ has to decide to exert a discrete educational effort, $e_{i} \in\{0,1\}$. The crucial feature of the model is that there are two opposite social norms regarding schooling behavior. One social norm values the behavior 'exerting an effort at school' (exerting $e_{i}=1$ in the model) and the other one prescribes the code of behavior 'not exerting an effort at school' (exerting $e_{i}=0$ ). Children differ with respect to their beliefs underlying the code of behavior, i.e. their preferences regarding the social norm. We call generation $t$ the individuals who are born at date $t$. There are $B_{t}$, respectively $N-B_{t}$, individuals of generation $t$ who believe in the 
values underlying the norm 'exerting an effort at school', respectively 'not exerting an effort at school'. For the sake of brevity, we call believers (implicitly 'education' believers) the individuals who believe in the norm 'exerting an effort at school' and non-believers (implicitly 'non-education' believers) those who believe in 'not exerting an effort at school'.

This formalization is consistent with the empirical findings of Liu et al. (2014) that individuals tend to conform to the education social norm of their friends. The existence of opposite social norms could be justified by the fact that pupils differ with respect to their identity which dictates particular educational behavior (see Akerlof and Kranton, 2000, Bishop, 2003, 2004 for models of slackers' or nerds' identity). Furthermore, ethnic identity can oppose the social norm accepted by the majority. Studies in the US have emphasized that African-American students may oppose values of studiousness and hard work as they are embraced by whites (see, for instance, Fodham and Ogbu, 1986, Fryer and Torelli, 2010).

We specify preferences following the works of Akerlof (1980), Naylor (1989) or Corneo (1993) which study how social norms can overcome the free rider problem arising under voluntary union trade membership or collective strike action. Precisely, preferences of a child $i$ living in area $j=1,2$ at date $t$ are defined as follows:

$\widehat{U}_{t}^{i, j}=p\left(e_{i}\right) U_{t+1}^{i}\left(w_{r}\right)+\left(1-p\left(e_{i}\right)\right) U_{t+1}^{i}\left(w_{p}\right)-\varepsilon_{i} c\left(e_{i}\right)+\left(e_{i}-\left(1-e_{i}\right)\right) b_{t}^{j} \widehat{h}$ if $i$ a believer, $\widetilde{U}_{t}^{i, j}=p\left(e_{i}\right) U_{t+1}^{i}\left(w_{r}\right)+\left(1-p\left(e_{i}\right)\right) U_{t+1}^{i}\left(w_{p}\right)-\varepsilon_{i} c\left(e_{i}\right)+\left(-e_{i}+\left(1-e_{i}\right)\right)\left(1-b_{t}^{j}\right) \tilde{h}$ if $i$ a non-believer with $U_{t+1}^{i}(w)$ the utility when $i$ is parent with income $w=w_{r}, w_{p}$. She earns income $w_{r}$, respectively $w_{p}<w_{r}$, with probability $p\left(e_{i}\right)$, respectively $1-p\left(e_{i}\right)$, while exerting effort $e_{i}$. We assume for the sake of simplicity that $p(1)=1$ and $p(0)=0 . U_{t+1}^{i}(w)$ will be specified in the following section while describing parents preferences. $\varepsilon_{i} c\left(e_{i}\right)$ is the cost of effort with $c(1)=c>0$ and $c(0)=0$ and $\varepsilon_{i}$ his innate ability. We assume that children differ with respect to their innate ability, $\varepsilon_{i}$. The lower the $\varepsilon_{i}$ the brighter the individual. $\varepsilon_{i}$ is assumed to be uniformly distributed on $[0,1]$.

The social norm component is $\left(e_{i}-\left(1-e_{i}\right)\right) b_{t}^{j} \widehat{h}$ for a believer and $\left(-e_{i}+\left(1-e_{i}\right)\right)\left(1-b_{t}^{j}\right) \widetilde{h}$ for a non-believer. Parameters $\widehat{h}$ and $\widetilde{h}$, respectively, capture the relative taste for the 'education' social norm, 'no education' social norm respectively. Both parameters $\widehat{h}$ and $\widetilde{h}$ are positive. We do not make any particular assumption about the magnitude of $\widetilde{h}$ with respect to $\widehat{h}$. We define the fraction of believers in area $j$ by $b_{t}^{j} \equiv B_{t}^{j} / L$. Hence, our specification of the social norm component implies that the obedience of the code of behavior the child believes in provides a reputation benefit. It is equal to $b_{t}^{j} \widehat{h}$ for a believer and $\left(1-b_{t}^{j}\right) \widetilde{h}$ for a non-believer. In contrast, 
the disobedience of the code of behavior incurs a stigmatization cost equal to $b_{t}^{j} \widehat{h}$ for a believer and $\left(1-b_{t}^{j}\right) \widetilde{h}$ for a non-believer. ${ }^{3}$ We depart from the literature on social norms by considering the existence of neighborhood effects. Incentives to follow the social norm depend on the fraction of people in the neighborhood believing in this norm. Precisely, for an individual, both reputation and stigmatization effects increase with the fraction of the neighborhood population with the same beliefs. We consider that beliefs rather than actions provide incentives to follow a social norm because actions reflect imperfectly the distribution of preferences for the social norm in the population. Actions are driven by various incentives and are impacted by shocks. In our model, some believers decide to not educate because they are disabled by an adverse ability shock $^{4}$. Nonetheless, we recognize that a persistent discrepancy between the number of individuals believing in a social norm and the number of individuals following its code of behavior may call into question the stability of the norm. As it will become clear when presenting the social norms dynamics, we require that a social norm is stable in the long run so that the number of agents who believe in it equal the number of agents who follow it.

We do not consider that cross-population effects such as neighboring with believers or nonbelievers, respectively, generate some reputation and stigmatization effects for non-believers or believers, respectively. Introducing such effects would not change the main results of the model. However, it will become clear later that there are still externalities between believers and nonbelievers generated by the location choice which will determine the socioeconomic composition of urban areas and thus the pattern of neighborhood effects.

Educational Choice. We assume that any child inherits the beliefs of his parent. Given these beliefs, she chooses her level of effort. A believer $i$ residing in area $j$ decides to educate if and only

\footnotetext{
${ }^{3}$ We could consider preferences with a parameter $h$ for the reputation benefit differing from a parameter $n$ for the stigmatization cost:

$$
\begin{aligned}
\widehat{U}_{t}^{j} & =p(e) U_{t+1}\left(w_{r}\right)+(1-p(e)) U_{t+1}\left(w_{p}\right)-\varepsilon c(e)+(s \widehat{h}-(1-s) \widehat{n}) b_{t}^{j} \text { for a believer, } \\
\widetilde{U}_{t}^{j} & =p(e) U_{t+1}\left(w_{r}\right)+(1-p(e)) U_{t+1}\left(w_{r}\right)-\varepsilon c(e)+(-s \widetilde{n}+(1-s) \widetilde{h})\left(1-b_{t}^{j}\right) \text { for a non-believer. }
\end{aligned}
$$

This would not change the main mechanisms of the model.

${ }^{4}$ We abstract from an asymmetric information setup where the level of effort may be a signal of individual preferences (see Bernheim, 1994, for a signalling model of social conformity).

We also do not formalize the decision taken by an individual to exert pressure in case peers deviate from the social norm (see Kandel and Lazear, 1992, for a model of peer pressure).
} 
if

$$
U_{t+1}^{i}\left(w_{r}\right)-\varepsilon_{i} c+b_{t}^{j} \widehat{h}>U_{t+1}^{i}\left(w_{p}\right)-b_{t}^{j} \widehat{h} .
$$

Letting $\Delta U_{t+1}^{i} \equiv U_{t+1}^{i}\left(w_{r}\right)-U_{t+1}^{i}\left(w_{p}\right)$, this amounts to

$$
\varepsilon_{i}<\widehat{\varepsilon}_{i}\left(b_{t}^{j}\right) \equiv \frac{\Delta U_{t+1}^{i}+2 b_{t}^{j} \widehat{h}}{c} .
$$

Neighborhood effects are crucial for the education decision. The larger the fraction of believers in the neighborhood the more likely the individual $i$ exerts effort $e_{i}=1$, that is $\widehat{\varepsilon}_{i}\left(b_{t}^{j}\right)$ is increasing with $b_{t}^{j}$ and $\widehat{\varepsilon}(0)=\Delta U_{t+1}^{i} / c<\widehat{\varepsilon}(1)=\left(\Delta U_{t+1}^{i}+2 \widehat{h}\right) / c$.

A non-believer $k$ residing in area $j$ decides to exert high effort if and only if

$$
U_{t+1}^{k}\left(w_{r}\right)-\varepsilon_{k} c-\left(1-b_{t}^{j}\right) \widetilde{h}>U_{t+1}^{k}\left(w_{p}\right)+\left(1-b_{t}^{j}\right) \widetilde{h}
$$

leading to

$$
\varepsilon_{k}<\widetilde{\varepsilon}_{k}\left(b_{t}^{j}\right) \equiv \frac{\Delta U_{t+1}^{k}-2\left(1-b_{t}^{j}\right) \widetilde{h}}{c} .
$$

The presence of non-believers in the area reduces incentives to exert high effort. The larger the fraction of non-believers, the lower the probability for the individual $k$ to exert effort $e_{k}=1$, i.e. $\widetilde{\varepsilon}_{k}\left(b_{t}^{j}\right)$ is decreasing with $1-b_{t}^{j}$. We have $\widetilde{\varepsilon}_{k}(0)=\left(\Delta U_{t+1}^{k}-2 \widetilde{h}\right) / c<\widetilde{\varepsilon}_{k}(1)=\Delta U_{t+1}^{k} / c$.

We see from (1) and (2) that $\widehat{h}$ and $\widetilde{h}$ measure the size of some social multiplier effect according to which small changes in private incentives are amplified by social interactions (see Becker and Murphy, 2000). For instance, a small decrease in the cost of education will lead to an increase in the number of believers who decide to educate, that is larger than without social interactions, i.e. $\left|\partial \widehat{\varepsilon}_{i}\left(b_{t}^{j}\right) / \partial c\right|=\left(\Delta U_{t+1}^{i}+2 b_{t}^{j} \widehat{h}\right) / c^{2}>\Delta U_{t+1}^{i} / c^{2}$. The reason is that a small decrease of the cost makes also neighbors choose education. This in turn increases incentives to follow the social norm $^{5}$. We will thus say that when $\widehat{h}>\widetilde{h}$, respectively $\widehat{h}<\widetilde{h}$, the social multiplier is higher, respectively lower, for believers than for non-believers.

\footnotetext{
${ }^{5}$ In fact, we could express the social multiplier if stigmatization costs and reputational benefits were proportional to the rate of education of believers or non-believers, respectively, living in the neighborhood, denoted by $\widehat{\lambda}_{t}^{j}$, respectively $\widetilde{\lambda}_{t}^{j}$ :

$$
\begin{aligned}
\widehat{U}_{t}^{j} & =p(e) U_{t+1}\left(w_{r}\right)+(1-p(e)) U_{t+1}\left(w_{p}\right)-\varepsilon c(e)+(e-(1-e)) \hat{\lambda}_{t}^{j} \widehat{h} \text { for a believer, } \\
\widetilde{U}_{t}^{j} & =p(e) U_{t+1}\left(w_{r}\right)+(1-p(e)) U_{t+1}\left(w_{p}\right)-\varepsilon c(e)+(-e+(1-e))\left(1-\widetilde{\lambda}_{t}^{j}\right) \widetilde{h} \text { otherwise. }
\end{aligned}
$$
}

Such a specification allowing for strategic complementarities would lead to the following thresholds

$$
\widehat{\varepsilon}_{i}\left(b_{t}^{j}\right) \equiv \frac{\Delta U_{t+1}^{i}+2 \widehat{\lambda}_{t}^{j} \widehat{h}}{c} \text { and } \widetilde{\varepsilon}_{k}\left(b_{t}^{j}\right) \equiv \frac{\Delta U_{t+1}^{k}-2\left(1-\widetilde{\lambda}_{t}^{j}\right) \widetilde{h}}{c}
$$




\subsection{Parents' location choice}

Parents differ with respect to both income and beliefs. Each parent chooses the family's location before her child experiences the ability shock and decides how much effort to devote to education. We make a limited altruism assumption so that parents are concerned by the expected income of their offspring. ${ }^{6}$ As it will become clear in the next section while presenting the social norms dynamics, the location decision of parents gives rise to a particular socioeconomic composition of each neighborhood and thus plays a key role in the dynamics of believers. Hence, at date $t$, given that $\varepsilon$ is uniformly distributed over $[0,1]$, any parent $i$ of generation $t-1$ with income $w_{z}, z=r, p$ and a child $k$ who lives in area $j$ has the following preferences:

$$
\begin{aligned}
& \widehat{U}_{t}^{i}\left(w_{z}\right)=u\left(w_{z}-\rho_{t}^{j}\right)+a\left(\int_{0}^{\widehat{\varepsilon}_{k}\left(b_{t}^{j}\right)} w_{r} d \varepsilon+\int_{\widehat{\varepsilon}_{k}\left(b_{t}^{j}\right)}^{1} w_{p} d \varepsilon\right) \text { if } i \text { is a believer, } \\
& \widetilde{U}_{t}^{i}\left(w_{z}\right)=u\left(w_{z}-\rho_{t}^{j}\right)+a\left(\int_{0}^{\widetilde{\varepsilon}_{k}\left(b_{t}^{j}\right)} w_{r} d \varepsilon+\int_{\widetilde{\varepsilon}_{k}\left(b_{t}^{j}\right)}^{1} w_{p} d \varepsilon\right) \text { otherwise }
\end{aligned}
$$

with $u($.$) the instantaneous utility function, \rho_{t}^{j}$ the rent paid to live in area $j$ at date $t, a$ an altruism parameter. $u($.$) is bounded, continuously differentiable, strictly increasing and concave$ over $\mathbb{R}_{+}$.

We look at the following equilibrium:

Definition 1 At date $t$, the urban configuration $\left[\rho_{t}^{*}, b_{t}^{1 *}\right]$ is an equilibrium such that, given her child's best educational choice, no parent wants to move.

Letting $\Delta w \equiv\left(w_{r}-w_{p}\right)$, at date $t$, any parent $i$ endowed with $w_{z}$ must solve the following program:

Hence, the impact of a small change of $c$ on $\hat{\lambda}_{t}^{j}$ and $\widetilde{\lambda}_{t}^{j}$ equals

$$
\frac{\partial \widehat{\lambda}_{t}^{j}}{\partial c}=\frac{\partial \widehat{\varepsilon}_{i}\left(b_{t}^{j}\right) / \partial c}{(1-2 \widehat{h} / c)} \text { and } \frac{\partial\left(1-\widetilde{\lambda}_{t}^{j}\right)}{\partial c}=\frac{\partial\left(1-\widehat{\varepsilon}_{i}\left(b_{t}^{j}\right)\right) / \partial c}{(1-2 \widetilde{h} / c)}
$$

leading to $\partial \widehat{\lambda}_{t}^{j} / \partial c>\partial \widehat{\varepsilon}_{i}\left(b_{t}^{j}\right) / \partial c$ and $\partial\left(1-\widetilde{\lambda}_{t}^{j}\right) / \partial c>\partial\left(1-\widehat{\varepsilon}_{i}\left(b_{t}^{j}\right)\right) / \partial c$ when the denominator is positive and less than 1 . The social multiplier equals $2 \widehat{h} / c$ and $2 \widetilde{h} / c$, for believers and non-believers, respectively. We do not use this model because, as we said before, we consider that actions reflect imperfectly the distribution of preferences for social norm in the the whole population.

${ }^{6}$ In Section 6, we study the implications of the assumption that parents are affected by the neighborhood's social norms. 


$$
\begin{gathered}
\max _{j} u\left(w_{z}-\rho_{t}^{j}\right)+a\left[\Delta w \widehat{\varepsilon}_{k}\left(b_{t}^{j}\right)+w_{p}\right] \text { if } i \text { is a believer, } \\
\max _{j} u\left(w_{z}-\rho_{t}^{j}\right)+a\left[\Delta w \widetilde{\varepsilon}_{k}\left(b_{t}^{j}\right)+w_{p}\right] \text { otherwise. }
\end{gathered}
$$

\subsection{Social Norms Dynamics}

We restrict our attention to the dynamics of believers, $B_{t}$, as the dynamics of non-believers $N-B_{t}$ is immediately deduced from the evolution of $B_{t}$. Following Akerlof (1980) "[...] if disobedience is more common, in all likelihood the values responsible for the observance of a social custom are less likely to be passed on from one generation to the next the greater is the disobedience." (p. 749), we consider that the number of believers born at date $t$ follow the social norm dynamics

$$
b_{t, t+1}^{j}-b_{t}^{j}=\lambda\left(b_{t}^{j}\right)-b_{t}^{j} \text { for any } j=1,2
$$

with $\lambda\left(b_{t}^{j}\right)$ the rate of education at date $t$ in area $j=1,2$ and $b_{t, t+1}^{j}$ the number of individuals of generation $t$, living in area $j$ at date $t$, and who are believers at date $t+1$. Hence, when $\lambda\left(b_{t}^{j}\right)>b_{t}^{j}$, the 'education' social norm spreads in the area $j$. These dynamics can be viewed as a stability process. In the long run, the social norm is stable in the sense that the number of individuals believing in the social norm equal the number of people following the prescribed code of behavior, i.e. $b_{t}^{j}=\lambda\left(b_{t}^{j}\right) .{ }^{7}$

A remark is worth mentioning. We assume that at each date adults choose their location. $b_{t, t+1}^{j}$ in (3) is obtained at an intermediate stage before generation $t$ individuals choose their place of residence. Hence, $b_{t, t+1}^{j}$ differs from $b_{t+1}^{j}$ which denotes the number of believers of generation $t$ once generation $t$ has made its residence choice. We depict the timing of events in Figure 1

\section{Insert Figure 1}

According to these dynamics, the generation $t$ with $B_{t}$ believers becomes adult at date $t+1$ with $B_{t+1}=L \sum_{j=1}^{2} b_{t, t+1}^{j}$ believers.

In order to obtain the rate of education, we make the following assumptions:

Assumption 1 Children are myopic in the sense that they do not anticipate that when adults (i) their beliefs may be different (ii) and they will pay a rent.

\footnotetext{
${ }^{7}$ The literature (see, for example, Akerlof, 1980, or Corneo, 1995) rather considers the following specification $b_{t, t+1}-b_{t}=H\left(\lambda\left(b_{t}\right)-b_{t}\right)$ with $H:[-1,1] \longrightarrow \mathbb{R}, H^{\prime}()>$.0 and $H(0)=0$. We consider a linear specification in order to conduct a tractable analysis of the dynamics.
} 
Assumption 1 puts aside two difficulties. First, while studying the educational choice of effort, given item (i), we do not need to specify the expected gains of education with respect to probabilities of becoming either a believer or a non-believer during adulthood. Given the social norms dynamics, the definition of these probabilities would require additional and ad hoc assumptions. Second, as expected gains of education do not depend on future rent, children do not have to anticipate the future urban equilibrium in order to make their choice of educational effort. It amounts to say that they are not aware of the fact that neighborhood social composition matters and has some intrinsic value. One could justify item (ii) by saying that children only interact with the neighborhood population and do not realize that the population may be unevenly distributed in the city. Hence they consider that belonging to a particular neighborhood has no effect on their educational effort. We thus assume that individuals expect to pay the cost of opportunity of land which is normalized to 0. Given parents preferences, Assumption 1 thus implies that both thresholds $\widehat{\varepsilon}_{i}\left(b_{t}^{j}\right)$ and $\widetilde{\varepsilon}_{k}\left(b_{t}^{j}\right)$ defined in (1) and (2) can be written as follows

$$
\begin{aligned}
\widehat{\varepsilon}_{i}\left(b_{t}^{j}\right) & =\widehat{\varepsilon}\left(b_{t}^{j}\right)=\frac{u\left(w_{r}\right)-u\left(w_{p}\right)+b_{t}^{j}(2 \widehat{h})}{c} \forall i, \\
\text { and } \widetilde{\varepsilon}_{k}\left(b_{t}^{j}\right) & =\widetilde{\varepsilon}\left(b_{t}^{j}\right)=\frac{u\left(w_{r}\right)-u\left(w_{p}\right)-\left(1-b_{t}^{j}\right)(2 \widetilde{h})}{c}, \forall k .
\end{aligned}
$$

Later on, we let $\Delta u \equiv u\left(w_{r}\right)-u\left(w_{p}\right)$. Obviously, for any $b_{t}^{j}$, we have $\widetilde{\varepsilon}\left(b_{t}^{j}\right)<\widehat{\varepsilon}\left(b_{t}^{j}\right)$ leading the rate of education of believers to be higher than that of non-believers.

Assumption 2 Parameters $c, w_{r}, w_{p}, \widetilde{h}, \widehat{h}$ and the function $u($.$) are such that (i) \Delta u / c<1$, (ii) $(c-\Delta u) / 2 \widehat{h}<1$, (iii) $\Delta u / 2 \widetilde{h}<1$.

Item (i) amounts to say that, ignoring social norms effects, returns to education are not sufficient to make the unablest individual exert high effort, i.e. $\Delta u-c<0$. Item (ii) tells us that if the urban area is exclusively inhabited by believers then the unablest believer is willing to exert high effort. Finally, item (iii) implies that when there are only non-believers in the neighborhod even the ablest non-believer does not exert high effort. Assumption 2 has some implications on the impact of the fraction of believers in the neighborhood on the educational rate of both the believers or the non-believers. Given both items (i) and (ii), we have $\widehat{\varepsilon}(0)<1<\widehat{\varepsilon}(1)$ ensuring that the fraction of believers exerting high effort lies between a strictly positive number less than 1 and 1 for any $b_{t}^{j} \in[0,1]$. Hence, below some threshold, any increase in the number of believers in the neighborhood strictly increases the number of believers who educate. Any fraction of believers in the neighborhood above this threshold leads all believers to get education. Furthermore, given 
both items (i) and (iii), we have $\widetilde{\varepsilon}(0)<0<\widetilde{\varepsilon}(1)<1$. It turns out that the fraction of nonbelievers exerting high effort lies between 0 and a strictly positive number lower than 1 . Hence, a minimal fraction of believers is needed to incite non-believers to exert educational effort. Once $b_{t}^{j}$ has reached this threshold, any further rise of believers in the neighborhood strictly increases the number of non-believers who decide to educate.

Given that $\varepsilon$ is uniformly distributed on the interval $[0,1]$, we can thus derive the fraction of children who are educated at date $t$ in area $j=1,2$, denoted by $\lambda\left(b_{t}^{j}\right)$,

$$
\lambda\left(b_{t}^{j}\right)=b_{t}^{j} \min \left[\widehat{\varepsilon}\left(b_{t}^{j}\right), 1\right]+\left(1-b_{t}^{j}\right) \max \left[0, \widetilde{\varepsilon}\left(b_{t}^{j}\right)\right] .
$$

Given (4) and (5), we have for $j=1,2$

$$
\lambda\left(b_{t}^{j}\right)=\min \left[\frac{(\Delta u) b_{t}^{j}+\left(b_{t}^{j}\right)^{2}(2 \widehat{h})}{c}, b_{t}^{j}\right]+\max \left[0, \frac{\Delta u\left(1-b_{t}^{j}\right)-\left(1-b_{t}^{j}\right)^{2}(2 \widetilde{h})}{c}\right] .
$$

We assume the following

Assumption 3 Parameters $c, w_{r}, w_{p}, \widetilde{h}, \widehat{h}$ and the function $u($.$) are such that$

$$
\frac{c-\Delta u}{2 \widehat{h}}>1-\frac{\Delta u}{2 \widetilde{h}}
$$

Assumption 3 avoids the case where we have for some $b_{t}^{j}$ corner situations for both believers and non-believers, i.e. there does not exist any $b_{t}^{j} \operatorname{such}$ that $\min \left[\widehat{\varepsilon}\left(b_{t}^{j}\right), 1\right]=1$ and $\max \left[0, \widetilde{\varepsilon}\left(b_{t}^{j}\right)\right]=0$. Assumption 3 thus guarantees that a variation of $b_{t}^{j}$ always leads to a change of the fraction of children exerting high effort.

Given Assumptions 1, 2 and 3, letting $\Delta h \equiv \widehat{h}-\widetilde{h}, A \equiv 1-(\Delta u / 2 \widetilde{h})$ and $C \equiv(c-\Delta u) / 2 \widehat{h}>A$, the fraction of children who educate then equals:

$$
\begin{aligned}
& \lambda\left(b_{t}^{j}\right)=\frac{(\Delta u) b_{t}^{j}+\left(b_{t}^{j}\right)^{2}(2 \widehat{h})}{c} \text { when } b_{t}^{j} \in[0, A] \\
& \lambda\left(b_{t}^{j}\right)=\left(b_{t}^{j}\right)^{2} \frac{2 \Delta h}{c}+b_{t}^{j} \frac{4 \widetilde{h}}{c}-\frac{2 \widetilde{h}}{c}+\frac{\Delta u}{c} \text { when } b_{t}^{j} \in[A, C] \\
& \lambda\left(b_{t}^{j}\right)=-\left(b_{t}^{j}\right)^{2} \frac{2 \widetilde{h}}{c}+b_{t}^{j}\left(1-\frac{\Delta u}{c}+\frac{4 \widetilde{h}}{c}\right)+\frac{\Delta u-2 \widetilde{h}}{c} \text { when } b_{t}^{j} \in[C, 1] .
\end{aligned}
$$

Hence, when the fraction of believers is low, i.e. $b_{t}^{j} \in[0, A]$, incentives to follow the 'education' social norm are weak, making a fraction of believers, those endowed with a high skill, exert high 
effort. By contrast, incentives to follow the 'no education' social norm are high for non-believers and none of them educate. The rate of education is then given by (6). When the fraction of believers is higher, i.e. $b_{t}^{j} \in[A, C]$, a higher fraction of believers educate and non-believers endowed with a high skill exert high effort. The rate of education is given by (7). Finally, when the fraction of believers is high, i.e. $b_{t}^{j} \in[C, 1]$, it turns out that all believers follow the 'education' social norm. A fraction of non-believers also exert high effort.

Let us stress that if items (ii) and (iii) of Assumption 2 were not satisfied then (8) and (6) respectively would not be considered and the dynamics would only be defined by (7). In such a case, as it will become clearer in Section 4, the model would not admit a multiplicity of steady states. Finally, Assumption 3 guarantees that there does not exist some $b_{t}^{j}<1$ such that $\lambda\left(b_{t}^{j}\right)=1$.

\section{Short-Run Equilibrium: Cultural Balance versus Cul- tural Divide}

According to Definition 1, the type of equilibrium that emerges crucially depends on the identity of individuals who are most willing to pay to live in a better neighborhood. Without loss of generality, we define area 1 as the one inhabited by a higher fraction of believers, i.e. $b_{t}^{1} \geq b_{t}^{2} \equiv\left(B_{t} / L\right)-b_{t}^{1}$. In order to study the equilibrium, it will be convenient to examine the bid-rent function which measures the willingness for a parent with income $w_{z}, z=r, p$ to pay to live in area 1 . It is denoted by $\widehat{\rho}^{z}\left(b_{t}^{1}\right)$ and $\widetilde{\rho}^{z}\left(b_{t}^{1}\right)$, for a believer and non-believer respectively, with income $w_{z}, z=r, p$. We assume without loss of generality that the rent in area 2 equals the opportunity cost of building a house which is normalized to 0 . Given (4) and (5), the bid rent of a parent with $w_{z}$ can be expressed as follows:

$$
\begin{aligned}
& u\left(w_{z}\right)-u\left(w_{z}-\widehat{\rho}^{z}\left(b_{t}^{1}\right)\right)=a\left(2 b_{t}^{1}-\frac{B_{t}}{L}\right)\left(\frac{2 \widehat{h}}{c}\right) \Delta w \text { for a believer } \\
& u\left(w_{z}\right)-u\left(w_{z}-\widetilde{\rho}^{z}\left(b_{t}^{1}\right)\right)=a\left(2 b_{t}^{1}-\frac{B_{t}}{L}\right)\left(\frac{2 \widetilde{h}}{c}\right) \Delta w \text { otherwise. }
\end{aligned}
$$

In a first step, we assume that the instantaneous utility function $u($.$) is linear so that the slope$ of the bid rent is not impacted by any income effect ${ }^{8}$. From (9) and (10), we have for any $z=r, p$

\footnotetext{
${ }^{8}$ The implications of a concave utility assumption are considered in Section 6.
} 


$$
\begin{aligned}
& \widehat{\rho}^{z}\left(b_{t}^{1}\right)=\widehat{\rho}\left(b_{t}^{1}\right)=a\left(2 b_{t}^{1}-\frac{B_{t}}{L}\right)\left(\frac{2 \widehat{h}}{c}\right) \Delta w \text { and } \\
& \widetilde{\rho}^{z}\left(b_{t}^{1}\right)=\widetilde{\rho}\left(b_{t}^{1}\right)=a\left(2 b_{t}^{1}-\frac{B_{t}}{L}\right)\left(\frac{2 \widetilde{h}}{c}\right) \Delta w
\end{aligned}
$$

Whatever their beliefs, parents are willing to pay to neighbor individuals who believe in the norm 'exerting an effort at school'. The higher $2 b_{t}^{1}-\left(B_{t} / L\right)$ the more attractive is area 1 . The reason is that given that parents value the expected income of their offspring they want to live in the neighborhood that most promotes education whatever their beliefs. Given this limited altruism assumption, parents who are non-believers are willing to pay to locate in the neigborhood of believers as it maximizes the probability that their child has a high expected income. In Section 6 , we relax the limited altruism assumption so that parents take care of the neighborhood social norm implying that it may be costly for parents if their child does not obey the social norm they believe in.

We introduce a stability condition which will prove useful in order to select an equilibrium.

Definition 2 Without loss of generality, let us assume that $B_{t} / 2 L \leq 1$. Consider an equilibrium $\left[\rho_{t}^{*}, b_{t}^{1 *}\right]$ with $B_{t} / 2 L \leq b_{t}^{1 *} \leq 1$. Take a small $\nu>0$. The equilibrium $\left[\rho_{t}^{*}, b_{t}^{1 *}\right]$ is stable if after a perturbation leading to $b_{t}^{1}=b_{t}^{1 *}+\nu$ or $b_{t}^{1}=b_{t}^{1 *}-\nu$, there are non-believers, believers respectively, in area 2 who are able to outbid believers, non-believers respectively, in order to live in area 1.

Hence, the stability condition hinges on the ranking of slopes of the bid rents which can be expressed as follows:

$$
\begin{aligned}
R\left(\widehat{h}, \rho_{t}\right) & \left.\equiv \frac{d \widehat{\rho}\left(b_{t}^{1}\right)}{d b_{t}^{1}}\right|_{U_{t}\left(w_{z}\right)=\bar{U}}=a \frac{4 \widehat{h}}{c} \Delta w \text { and } \\
R\left(\widetilde{h}, \rho_{t}\right) & \left.\equiv \frac{d \widetilde{\rho}\left(b_{t}^{1}\right)}{d b_{t}^{1}}\right|_{U_{t}\left(w_{z}\right)=\bar{U}}=a \frac{4 \widehat{h}}{c} \Delta w .
\end{aligned}
$$

leading to

$$
R\left(\widehat{h}, \rho_{t}\right) \gtreqless R\left(\widetilde{h}, \rho_{t}\right) \text { if and only if } \widehat{h} \gtreqless \widetilde{h} \text {. }
$$

We can first offer the following

Proposition 1 The symmetric equilibrium $\left[\rho_{t}^{*}=0, b_{t}^{1 *}=B_{t} / 2 L\right]$, called culturally-balanced, always exists. It is the unique stable equilibrium if and only if $\widehat{h} \leq \widetilde{h}$. 
Proofs are relegated to the Appendix. There is always an equilibrium where the population of believers is distributed evenly among both areas. The mix of social norms is the same in both neighborhoods. It turns out that individuals, whatever their income and beliefs, are indifferent between the two residential areas. The equilibrium rate of education, that is $\lambda\left(B_{t} / 2 L\right)$, is the same in both urban areas and is given by one of the three equations (6), (7) and (8) depending on the value of $B_{t} / 2 L$.

Let us consider a migration of $\nu$ believers from area 2 to area 1 and a migration of $\nu$ nonbelievers in the reverse direction. When the social multiplier is higher for believers implying that $R\left(\widehat{h}, \rho_{t}\right)>R\left(\widetilde{h}, \rho_{t}\right)$, believers find it worthwhile to migrate to area 1 preventing the culturallybalanced equilibrium from being restored. Otherwise, non-believers are able to outbid believers to live in urban area 1 , thus correcting the perturbation.

The following Proposition focuses on another type of equilibrium

Proposition 2 A culturally-divided equilibrium exists if and only if $\widehat{h}>\widetilde{h}$. If $B_{t}<L, b_{t}^{1 *}=B_{t} / L$ and $b_{t}^{2 *}=0$. If $B_{t}>L, b_{t}^{1 *}=1$ and $b_{t}^{2 *}=\left(B_{t} / L\right)-1$. It is always stable.

When the social multiplier is higher for believers, another type of urban equilibrium, called culturally-divided equilibrium, exists. It is such that the fraction of believers is larger in area 1 than in area 2. Two types of cultural clash which are depicted in Figure 2 arise. The city on the left arises when the whole population is comprised of a majority of non-believers, i.e. $B_{t} \leq L$. All believers are located in area 1 , that is $b_{t}^{1}=B_{t} / L$. Population in area 2 unanimously rejects education as $b_{t}^{2}=0$ and deprives the youth of incentives to educate. Depending on $B_{t} / L$, the equilibrium rate of education in area $1, \lambda\left(b_{t}^{1}\right)$, is given by one of the three equalities (6) or (7) or (8). Whereas the educational rate in urban area 2 is nil. The city on the right arises when $B_{t}>L$. The cultural clash is such that urban area 1 is only inhabited by believers who unanimously promote education. Both social norms are present in urban area 2. We have $\lambda\left(b_{t}^{1}\right)=1$ and the equilibrium rate of education in area 2 is given by either (6), or (7) or (8).

\section{Insert Figure 2}

As far as we know, the empirical evidence on peer effects in education does not allow to draw any clear-cut conclusion about the magnitude of $\widehat{h}$ with respect to $\widetilde{h}$. It is thus difficult to claim that one type of urban equilibrium is more likely to arise than the other one.

For instance, Bishop (2003)'s results suggest that $\widehat{h}$ and $\widetilde{h}$ have the same magnitude. Using data from the Educational Excellence Alliance's survey of Student Culture, Bishop (2003) finds that 
the increase of harassment has the same magnitude whether a student is above or below the school norm: "[...] students who were 1.5 SDs above the mean [...] on GPA and the commitment indices were harassed 43 times a year, a 42 percent increase from the baseline student. Those hanging out in cliques that were 1.5 SDs below the school mean on GPA and academic commitment were harassed about 39 times a year a 30 percent increase over the baseline level." (p.51, Bishop, 2003).

However, it is likely that pupils attending schools such as KIPP academies and other charter schools acquire preferences such that $\widehat{h}>\widetilde{h}$. Although no empirical study has tested this hypothesis, it is recognized that these schools enforce pro-learning social norms and make their pupils acquire pro-education preferences (see Angrist et al. 2013 or Curto and Fryer, 2014). More generally, schools are social institutions that promote social goals and affect students' identity. According to Akerlof and Kranton (2002), schools can act in order to delineate prescriptions for student behavior and ensure that students identify with the school and its ideals.

\section{Social Norms Dynamics in the Culturally-Divided City}

We analyze the dynamics of social norms under segregation. We thus assume that $\widehat{h}>\widetilde{h}$ leading the cultural-divided city to arise at each date $t$. From (3), we have:

$$
B_{t+1}=B_{t}+L \sum_{j=1}^{2}\left(\lambda\left(b_{t}^{j}\right)-b_{t}^{j}\right) .
$$

The 'education' social norm dynamics when the culturally-divided equilibrium arises at each date $t$ can be expressed as follows:

$$
B_{t+1}\left\{\begin{array}{c}
=B_{t}+L\left[\lambda\left(\frac{B_{t}}{L}\right)-\frac{B_{t}}{L}+\lambda(0)-0\right] \text { when } B_{t}<L \\
=B_{t}+L\left[\lambda(1)-1+\lambda\left(\frac{B_{t}}{L}-1\right)-\left(\frac{B_{t}}{L}-1\right)\right] \text { when } L \leq B_{t} \leq 2 L .
\end{array}\right.
$$

Given (6) and (8), we have $\lambda(0)=0$ and $\lambda(1)=1$. We obtain:

$$
B_{t+1}\left\{\begin{array}{c}
=L \lambda\left(\frac{B_{t}}{L}\right) \text { when } B_{t}<L \\
=L \lambda\left(\frac{B_{t}}{L}-1\right)+L \text { when } L \leq B_{t} \leq 2 L
\end{array}\right.
$$

where $\lambda\left(B_{t} / L\right)$ and $\lambda\left(\left(B_{t} / L\right)-1\right)$ are given by equations (6)-(8). In this dynamic setup, we have potentially multiple long-run equilibria. We will say that a long-run equilibrium is locally stable if for any $B_{t}$ in the vicinity of the steady state the population of believers converges to the steady state. ${ }^{9}$

\footnotetext{
${ }^{9}$ We have thus two different notions of stability, the dynamic one and the spatial one which is specified in Definition 2. When we speak about the stability of the steady-state equilibrium we refer to the dynamic one.
} 
We can then offer the following:

Proposition 3 When a culturally-divided equilibrium emerges at each date t, there are three locally stable long-run equilibria: $B_{1}^{C D}=0, B_{2}^{C D}=L, B_{3}^{C D}=2 L$.

Proposition 3 allows us to depict the following social norms dynamics implied by a culturallydivided city. The complete characterization of the dynamical system is provided in the Appendix.

\section{Insert Figure 3}

The dynamics exhibit three history-dependent stable steady states. Also depicted in the graph are two unstable steady states $B_{1}^{\star \star}$ and $B_{2}^{\star \star}$ with $0<B_{1}^{\star \star}<L$ and $L<B_{2}^{\star \star}<2 L$. Consider the case where initially all believers inhabit area 1, i.e. $0 \leq B_{0} \leq L$. When $0 \leq B_{0} \leq B_{1}^{\star \star}$, the initial number of believers is not sufficient to generate incentives that lead to a spread of the 'education' social norm. Hence, in the long run, the whole population becomes non-believer and depreciates education. When $B_{1}^{\star \star} \leq B_{0} \leq L$, the city reaches a steady state such that the area 1 is populated exclusively by believers. A cultural clash arises in the city as area 2 promotes exclusively the 'no education' social norm. If now the number of believers is larger than $L$ then, according to Proposition 2, believers are located in both urban areas. When $L \leq B_{0} \leq B_{2}^{\star \star}$, believers in area 2 are not numerous enough to promote the 'education' social norm and thus urban area 2 ends up with no believers in the long run. On the whole, when $B_{1}^{\star \star} \leq B_{0} \leq B_{2}^{\star \star}$, in the long run, inhabitants in urban area 2 unanimously depreciate education and fall in a poverty trap. When $B_{2}^{\star \star} \leq B_{0} \leq 2 L$, the culturally-divided equilibrium is such that believers in area 2 are numerous enough to generate incentives to invest into education. The number of believers expands in the whole population and in the long run, the city is inhabited by believers and the level of education is maximized and equal to $B_{3}^{C D}=2 L{ }^{10}$

For each steady state, the long-run distribution of income is the following:

$$
\begin{aligned}
& \text { at } B_{1}^{C D}, N^{r}=0 \text { and } N^{p}=2 L \\
& \text { at } B_{2}^{C D}, N^{r}=L \text { and } N^{p}=L \\
& \text { at } B_{3}^{C D}, N^{r}=2 L \text { and } N^{p}=0 .
\end{aligned}
$$

\footnotetext{
${ }^{10}$ In the graph, $B_{1}^{\star \star} \in[L A, L C]$ and $B_{2}^{\star \star} \in[L A+L, L C+L]$. This may not be always the case. However, we show that $B_{1}^{\star \star} \in[L A, L]$ and $B_{2}^{\star \star} \in[L+L A, 2 L]$ and when $B_{1}^{\star \star} \in[L A, L C]$, respectively $B_{1}^{\star \star} \in[L C, L]$, we have $B_{2}^{\star \star} \in[L A+L, L C+L]$, respectively $B_{2}^{\star \star} \in[L C+L, 2 L]$.
} 
Obviously, the steady state where the 'no education' social norm is the rule of behavior will lead to the highest poverty rate while the steady state promoting education will lead to a homogeneously rich population. For these two steady states, the education rate is the same in both urban areas and the rent paid in area 1 becomes nil. Moreover, the city reaching $B_{2}^{C D}$ is characterized by an intermediate number of poor people and exhibits an uneven distribution of education as both urban areas are opposed with respect to the prevailing social norm.

Hence, following Crane (1991) terminology, the dynamics exhibit epidemics of social norm. The 'education' social norm spreads in one urban area or in the entire city if the population of believers reaches a threshold value. On the contrary, if the population of believers stays below a threshold the population tends to a low-level equilibrium with the 'no education' social norm prevailing in the city. Given these tipping dynamics, small differences in initial conditions may lead to dramatic differences in education rates and inequality dynamics. This result is consistent with empirical findings of existence of tipping points. A first strategy adopted by Crane (1991) to test the existence of tipping dynamics was to estimate the effects of neighborhood quality on dropping out and teenage childbearing. Crane (1991) shows that this relationship is nonlinear, leading neighborhood effects to be much larger in urban ghettos than in more favorable neighborhoods. In his review of the US literature, Galster (2002) concludes that neighborhood poverty has no effect on crime and school drop-out when the poverty rate does not exceed $20 \%$ whereupon the externality grows rapidly until the poverty rate reaches approximately 40\%. Above this last threshold, subsequent increases in the poverty are innocuous. A second approach by Card, Mas and Rothstein (2008) in order to test for race-based tipping dynamics uses decadal changes in neighborhood racial composition. They find strong evidence of tipping over 1970s, 1980s and 1990s with a distribution of tipping points ranging from $5 \%$ to $20 \%$ minority share.

\section{Does a Culturally-Balanced City Lead to Higher Edu- cation?}

Let us now study the dynamics under integration. Given (16), when $b_{t}^{1}=b_{t}^{2}=B_{t} / 2 L$ at each date $t$ then the social norm dynamics writes down:

$$
B_{t+1}=B_{t}+2 L\left(\lambda_{t}\left(\frac{B_{t}}{2 L}\right)-\frac{B_{t}}{2 L}\right)
$$

where $\lambda\left(B_{t} / 2 L\right)$ is given by equations (6)-(8). 
Proposition 4 When a culturally-balanced equilibrium emerges at each date t, there are two locally stable long-run equilibria $B_{1}^{C B}=0, B_{2}^{C B}=2 L$.

The dynamics exhibit two history-dependent stable steady states. If the city starts with a population of believers above the threshold $B^{\star}$ depicted in Figure 4 then incentives to exert high effort are sufficiently high in both urban areas leading the 'education' social norm to spread in the population. Hence, in the long run, all individuals believe in this social norm, $B_{2}^{C B}=2 L$. On the contrary, when the initial population of believers is below $B^{\star}$ then the 'education' social norm vanishes. In the long run, the whole city population adheres to the 'no education' social norm.

\section{Insert Figure 4}

Each steady state is characterized by a particular long-run distribution:

$$
\begin{aligned}
& \text { at } B_{1}^{C B}=0, N^{r}=0 \text { and } N^{p}=N \\
& \text { at } B_{2}^{C B}=2 L, N^{r}=N \text { and } N^{p}=0 .
\end{aligned}
$$

We now turn to the issue whether the culturally-balanced city always perform better than a culturally-divided one in the long run regarding to the rate of education. The following figure is a superposition of social norms dynamics depicted in both Figures 3 and 4 and exhibits a particular case that may arise depending on parameter values of $c, \Delta u, \widetilde{h}, \widehat{h}$. The Appendix provides a characterization of all possible cases.

\section{Insert Figure 5}

Depending on initial conditions, the culturally-balanced city and the culturally-divided city may reach very different steady states. For instance, consider the case where $B_{1}^{\star \star} \leq B^{\star} \leq B_{2}^{\star \star}$ and let us start with $B_{0}$ such that $B_{1}^{\star \star}<B_{0}<B^{\star}$. Hence, the culturally-divided city and culturallybalanced city, reaches the steady-state $B_{2}^{C D}=L$ and $B_{1}^{C B}=0$ respectively. The culturallydivided city performs better in the long run than the culturally-balanced city because in case of concentration of the 'education' social norm in area 1 the initial number of believers is sufficient for the 'education' social norm to spread in urban area 1 while in case of cultural balancedness the 
same number of believers is too disseminated in the city for the "education" social norm to spread. However, if the economy starts with $B_{0}$ such that $B^{\star}<B_{0}<B_{2}^{\star \star}$, the culturally-balanced city would perform better than the culturally-divided one. The culturally-balanced city would endup with a maximized rate of education while the culturally-divided city would exhibit long-run inequality between both urban areas.

Furthermore, Figure 5 highlights that a culturally-balanced city may involve a dynamic tradeoff, that is the educational rate would be maximized in the short run but would be lower than under segregation in the long run. Given the specification of the social norms dynamics, $B_{t+1}$ equals the number of people who educate at date $t$. Hence we can see that if $B^{\star}>L$ which arises if $\Delta h<c-2 \Delta u$, then there are values of $B_{t}$ such that the rate of educational is higher at date $t$ in the culturally balanced city but converges to the steady state $B_{1}^{C B}=0$ rather than $B_{2}^{C D}=L .^{11}$

We are not aware of any empirical evidence supporting that integration leads to a general erosion of norms in favor of education. The strategy in order to test this result requires that, once an integration policy is implemented, the urban equilibrium remains integrated along the transitional path of social norms dynamics. However, the difficulty is that integration policies do not only impact local externalities but also induce some inhabitants to respond by leaving urban areas targeted by these policies. White flight caused by desegregation plans implemented in the US is a good illustration that integration policies cause migration of white families to whiter urban areas (see for instance Reber, 2005, for empirical evidence of the effects of court-ordered desegregation plans on white flight).

Nonetheless, the potential negative effect of integration is consistent with empirical findings of social norms influence that once the share of disadvantaged populations exceeds some threshold then negative effects occur (see Galster, 2002 and Galster 2010, for reviews). Hence, when there are non-linear relationships between neighborhood poverty rates and individual behavioral outcomes, poverty deconcentration policies should proceed with caution when implementing the degree of neighborhood social mix. According to Galster (2002), if behavioral problems are related to neighborhood poverty rates within a range of approximately 15-40\% of poverty rate, "This implies that net social benefits will be larger if neighborhoods with greater than roughly $15 \%$ poverty rates are replaced with (an appropriately larger number) of neighborhoods having less than 15\% poverty rates. However, net social benefits will be smaller if neighborhoods with greater than about $40 \%$ poverty rates are replaced with (an appropriately larger number) of neighborhoods having between about 15-40\% poverty rates. Put more bluntly in policy terms, unless very low-poverty

\footnotetext{
${ }^{11}$ See Bénabou (1996a) for an elegant formal treatment of this dynamic trade-off.
} 
neighborhoods can be opened up for occupation by the poor, deconcentration efforts should halt, because merely transferring the poor from high- to moderate-poverty neighborhoods is likely to be socially inefficient." (p. 322, Galster, 2002).

Finally, a possible empirical investigation of our model would be to see whether the tipping dynamics depend on the degree of urban segregation. Indeed, our model highlights that the socioeconomic organization of the city drives specific dynamics with particular threshold values, although this result relies on particular parameter values and on the specification of the model.

\section{Extended Altruism, Income Effect and Multiple Urban Equilibria}

We extend the model so that (i) parents are also affected by the neighborhood's norms of education and (ii) the utility is strictly concave. We study the implications of these assumptions on the urban equilibria that emerge. The characteristics of the social norms dynamics are not modified by these assumptions. Parents' preferences are now written as follows:

$$
\begin{aligned}
& \widehat{U}_{t}^{i}\left(w_{z}\right)=u\left(w_{z}-\rho_{t}^{j}\right)+a\left(\int_{0}^{\widehat{\varepsilon}_{k}\left(b_{t}^{j}\right)}\left(w_{r}+b_{t}^{j} \widehat{h}\right) d \varepsilon+\int_{\widehat{\varepsilon}_{k}\left(b_{t}^{j}\right)}^{1}\left(w_{p}-b_{t}^{j} \widehat{h}\right) d \varepsilon\right) \text { if } i \text { is a believer, } \\
& \widetilde{U}_{t}^{i}\left(w_{z}\right)=u\left(w_{z}-\rho_{t}^{j}\right)+a\left(\int_{0}^{\widetilde{\varepsilon}_{k}\left(b_{t}^{j}\right)}\left(w_{r}-\left(1-b_{t}^{j}\right) \widetilde{h}\right) d \varepsilon+\int_{\widetilde{\varepsilon}_{k}\left(b_{t}^{j}\right)}^{1}\left(w_{p}+\left(1-b_{t}^{j}\right) \widetilde{h}\right) d \varepsilon\right) \text { otherwise. }
\end{aligned}
$$

This specification amounts to say that any parent benefits from reputation if her child follows the social norm he believes in and suffers from stigmatization in case her child deviates from the social norm. Straightforward computations lead to the following slopes of bid rents

$$
\begin{aligned}
& R\left(w_{z}, \widehat{h}, \rho_{t}, B_{t}\right)=a \frac{4 \widehat{h}}{c u^{\prime}\left(w_{z}-\rho_{t}\right)}\left[\Delta w+\Delta u+2 \widehat{h} \frac{B_{t}}{L}-\frac{c}{2}\right] \text { for } z=r, p \text { and } \\
& R\left(w_{z}, \widetilde{h}, \rho_{t}, B_{t}\right)=a \frac{4 \widetilde{h}}{c u^{\prime}\left(w_{z}-\rho_{t}\right)}\left[\Delta w+\Delta u-2 \widetilde{h}\left(2-\frac{B_{t}}{L}\right)-\frac{c}{2}\right] \text { for } z=r, p .
\end{aligned}
$$

Hence, both dimensions of heterogeneity, income and beliefs, impact their willingness to pay to live in area 1. Taking beliefs as given, bid rent is steeper for a rich parent. This is due to the concavity of $u($.$) . Thus a rich agent outbids the poorer one. If now beliefs change, the bid-rent$ differential between a believer endowed with $w_{z}$ and a non-believer with $w_{z^{\prime}}$ can be expressed as 
follows

$$
\begin{aligned}
R\left(w_{z}, \widehat{h}, \rho_{t}, B_{t}\right)-R\left(w_{z^{\prime}}, \widetilde{h}, \rho_{t}, B_{t}\right)= & \frac{4 a}{c u^{\prime}\left(w_{z}-\rho_{t}\right)}\left[(\widehat{h}-\widetilde{h})\left(\Delta w+\Delta u-\frac{c}{2}\right)+2 \widehat{h}^{2} \frac{B_{t}}{L}+2 \widetilde{h}^{2}\left(2-\frac{B_{t}}{L}\right)\right. \\
& \left.+\left[1-\frac{u^{\prime}\left(w_{z}-\rho_{t}\right)}{u^{\prime}\left(w_{z^{\prime}}-\rho_{t}\right)}\right]\left[\Delta w+\Delta u-\frac{c}{2}-2 \widetilde{h}\left(2-\frac{B_{t}}{L}\right)\right]\right] . \quad
\end{aligned}
$$

It turns out that new incentives drive the location choice. If both individuals have the same income, the differential is given by the first line of (19) where two forces are stressed: weighted net returns to education denoted by $(\widehat{h}-\widetilde{h})(\Delta w+\Delta u-(c / 2))$ and social norms effect equal to $2 \widehat{h}^{2}\left(B_{t} / L\right)+2 \widetilde{h}^{2}\left(2-\left(B_{t} / L\right)\right)$. First, when the returns to education are positive, i.e. $\Delta w+$ $\Delta u-(c / 2) \geq 0$, and the social multiplier is higher for believers, i.e. $\widehat{h} \geq \widetilde{h}$, both forces make the rent differential be positive. It turns out that believers find more attractive to live in urban area 1 and outbid non-believers. Second, when returns to education are negative and the social multiplier is higher for non-believers, believers outbid non-believers to live in urban area 1 . The logic behind this result is slightly different than in the first case as, now, non-believers find more attractive to live in urban area 2. However, it is also possible to have cases where both forces act in opposite direction and make the bid-rent differential is negative. When returns to education are positive, non-believers may be more willing to live in urban area 1 than believers. This case can arise when the social multiplier is higher for non-believers, i.e. $\widehat{h}<\widetilde{h}$, valuing more the weighted net returns to education and when the maximal value of the social norm effect is lower than the negative weighted returns to education, i.e. $(\widehat{h}-\widetilde{h})(2 \Delta w-(c / 2))+4 \widetilde{h}^{2}<0$. In such a case, non-believers are eager to suffer more from stigmatization in order to benefit from a better environment for education. When returns to education are negative, believers may be more willing to live in urban area 2. This case arises when the social multiplier is higher for believers and the maximal positive social norm effect is outweighed by the negative weighted returns to education, i.e. $(\widehat{h}-\widetilde{h})(2 \Delta w-(c / 2)+4(\widehat{h}+\widetilde{h}))+4 \widetilde{h}^{2}<0$. In such a case, given stigmatization costs and reputation benefits are modest, believers prefer their offspring to live in a low-education neighborhood environment.

If now we consider a believer and a non-believer differing with respect to their income the two last brackets of (19) must also be taken into account to derive the sign of the bid-rent differential. Both last brackets capture the income effect generated by the concavity of $u($.$) . Hence, when$ individuals differ with respect to both dimensions, it is likelier that bid-rent functions cross more than once and that multiple stable urban equilibria arise. 
We can then offer the following:

Proposition 5 At any date $t$,

(i) The culturally-balanced city $\left[\rho_{t}^{*}=0, b_{t}^{1 *}=B_{t} / 2 L\right]$ always exists. It is stable if and only if $R\left(w_{z}, \widehat{h}, 0, B_{t}\right)<R\left(w_{z^{\prime}}, \widetilde{h}, 0, B_{t}\right)$ for $z \neq z^{\prime}=r, p$.

(ii) For some values of $c, w_{r}, w_{p}, \widetilde{h}, \widehat{h}, a$ and depending on the distribution of income and beliefs, a culturally-divided equilibrium with $b_{t}^{1 *}>b_{t}^{2 *}$ exists and is stable.

(iii) For some values of $c, w_{r}, w_{p}, \widetilde{h}, \widehat{h}, a, B_{t} / L$, the culturally-balanced equilibrium is stable and the culturally-divided equilibrium exists.

This Proposition highlights a richer pattern of urban equilibria. According to item (i), the existence of the culturally-balanced equilibrium still holds. Stability requires that non-believers are able to outbid believers in order to counterbalance the perturbation. Item (ii) stresses various configurations of culturally-divided equilibria. Precisely, existence and stability of the culturallydivided equilibrium rely first on values taken by the slopes of the bid-rent function, second, on the demographic characteristics of the population, i.e. the size of both the population of believers and non-believers. The Appendix provides the conditions on the bid-rent differential and demographics so that a culturally-divided city exists.

\section{Insert Figure 6}

We denote by $\widehat{N}_{t}^{z}\left(\widehat{N}_{t}^{z, j}\right)$, respectively $\widetilde{N}_{t}^{z}\left(\widetilde{N}_{t}^{z, j}\right)$, the number of parents with income $w_{z}$ who are believers, non-believers, in the whole population (in area $j$ ). Figure 6 displays two configurations of a culturally-divided city that possibly exist when the population of rich believers is smaller than $L$ and when the rich non-believers are able to outbid poor believers. In addition to the cultural divide, the city on the left exhibits income segregation where all the poor live in area 2. Hence, area 1 is inhabited by a larger fraction of believers than in area 2 and it is also homogeneously rich. Nevertheless, area 2 is populated by a fraction of believers that helps individuals to get education. Depending on the value of $b_{t}^{j}$, the equilibrium rate of education in area $j, \lambda\left(b_{t}^{j}\right)$, is given by either (6), or (7) or (8). As $b_{t}^{1}>b_{t}^{2}$, we have $\lambda\left(b_{t}^{1}\right)>\lambda\left(b_{t}^{2}\right)$.

The city on the right arises when the whole population is comprised of a majority of poor nonbelievers, i.e. $\widetilde{N}_{t}^{p}>$ L. Both the rich and the believers populations are located in area 1, that is 
$b_{t}^{1}=B_{t} / L$. Depending on $B_{t} / L$, the equilibrium rate of education in area $1, \lambda\left(b_{t}^{1}\right)$, is given by one of the three equalities (6) or (7) or (8). The population in area 2 unanimously rejects education as $b_{t}^{2}=0$. According to (6), no non-believer educates. Furthermore, area 2 concentrates poverty. In both urban configurations, the rich population has a larger opportunity to benefit from better neighborhood effects than the poorer one.

On the contrary, when the poor believers outbid rich non-believers, a different configuration of the culturally-divided city may arise where all believers segregate in area 1 leading area 2 to promote the opposite social norm. This cultural clash leads to an educational gap such that $\lambda\left(b_{t}^{2}\right)=0$ and $\lambda\left(B_{t} / L\right)$ is given by (6), (7) or (8) depending on the level of $B_{t} / L$. This urban equilibrium is depicted below.

\section{Insert Figure 7}

Let us mention that an increase in the income inequality may lead to a dramatic change of the urban configuration. The urban configuration in Figure 7 is obtained when $R\left(w_{r}, \widetilde{h}, \rho_{t}, B_{t}\right)-$ $R\left(w_{p}, \widehat{h}, \rho_{t}, B_{t}\right)<0$. An increase in income inequality, assimilated to an increase in the income gap between $w_{r}$ and $w_{p}$, can reverse the ranking between the slopes of both bid-rent curves, i.e. $R\left(w_{r}, \widetilde{h}, \rho_{t}, B_{t}\right)-R\left(w_{p}, \widehat{h}, \rho_{t}, B_{t}\right)>0$. It thus turns out that the city on the left of Figure 6 can emerge. Hence, an increase in income inequality can lead to a more balanced distribution of believers in the whole city.

Finally, when bid rents cross more than once, an urban configuration where poor believers and rich non-believers are both indifferent between living in area 1 or area 2 exists. All rich believers who are the highest bidders live in area 1 while the poor non-believers who are the lowest bidders inhabit area 2. It is depicted below. ${ }^{12}$

\section{Insert Figure 8}

In the Appendix we provide a numerical example highlighting that bid-rent functions can cross more than once giving rise to multiple stable urban equilibria.

Several remarks about the bid-rent differential are worth mentioning. First, an increase in

\footnotetext{
${ }^{12}$ The interesting issue of selecting a particular equilibrium among a set of stable equilibria is beyond the scope of our paper.
} 
returns to education can also affect the bid-rent differential. Formally, we have

$$
\partial \frac{R\left(w_{z}, \widehat{h}, \rho_{t}, B_{t}\right)-R\left(w_{z^{\prime}}, \widetilde{h}, \rho_{t}, B_{t}\right)}{\partial\left(\Delta w+\Delta u-\frac{c}{2}\right)}=\frac{a 4}{c}\left[\frac{\widehat{h}-\widetilde{h}}{u^{\prime}\left(w_{z}-\rho_{t}\right)}+\frac{1}{u^{\prime}\left(w_{z}-\rho_{t}\right)}-\frac{1}{u^{\prime}\left(w_{z^{\prime}}-\rho_{t}\right)}\right]
$$

highlighting that a marginal increase in returns to education has two effects: one being the change in the weighted net returns to education and the second being the change in the income effect. Depending on the income gap and the difference between $\widehat{h}-\widetilde{h}$, this derivative may be positive or negative. What is important to stress is that a change in returns to education can reverse the ranking of the bid-rent slopes and lead to a dramatic change of the city. Second, the bid-rent differential being time-dependent, the urban equilibrium may change along the transitional path. Depending on the short-run dynamics of $B_{t}$, the sign of the bid-rent differential can change leading the urban configuration to be modified.

Finally, the bid-rent differential (19) sheds light on the design of public policies favoring social integration. Imagine that parameters are such that the city is culturally-divided but, in both the short run and the long run, integration is preferable in order to maximize education. Hence, a central authority would have to design a public policy that would restore the stability of the culturally-balanced city. According to (19), one can influence the income effect. Housing subsidies targeted on the poor could make poor non-believers more willing than rich believers to reside in area 1 . The urban area 1 would then be inhabited by both poor non-believers and poor believers providing the former more incentives to educate. ${ }^{13}$

\section{Conclusion}

In a multicommunity model, we study how social norms on educational behavior spread in the city. When young, any individual who believes in a social norm has to determine her educational effort depending on some peer pressure produced by the fraction of people in the neighborhood believing in the same social norm. When an adult, any individual chooses the place of residence for the whole family taking into account the educational prospect of her offspring. At each date, it turns out that multiple urban equilibria arise. First, there exists the culturally-balanced equilibrium

\footnotetext{
${ }^{13}$ The Moving to Opportunity Program, Section 8 Housing Choice Voucher Program or the Low-Income Tax Credit are examples of such housing-subsidies programs implemented in the US.

Of course, it would be effective to change social norms. Charter schools that feature a long-school day, an extended school year and strict behavior norms aim to fight against social norms discrediting education (see recent works of Angrist et al., 2013 and Curto and Fryer, 2014, on evaluation of the causal impact of these policies on academic achievement).
} 
where all urban areas are similar with respect to the produced neighborhood effects, that is to the fraction of people obeying a particular social norm. Second, there may also exist culturallydivided equilibria such that the composition of social norms followed by the population differs among urban areas. In particular, some culturally-divided equilibria with a dramatic cultural contrast may arise: either all believers, or all non-believers, live in the same urban area. We then study the social norms dynamics implied by the culturally-divided city. We show that the dynamics exhibit epidemics so that if the fraction of people believing in a particular social norm is above a certain threshold then this social norm spreads in the urban area and possibly in the whole city. We also show that for some initial conditions the culturally-divided city experiences higher education in the long run than the culturally-balanced city.

Although special attention has been paid to education, this model could also be applied to studying social problems such as drug consumption, teenage pregnancy, crime activities, etc. and their diffusion in the city. In particular, the dynamic setup can help understand why public policies (punishment policies for instance) may be ineffective to fight against social pathologies because of the strong influence of the past. The model could also justify the fact that integration policies could be good substitutes to fight against social problems.

Finally, this model relies on the specific dynamic mechanism that the social norm expands if the number of people following it exceeds the number of believers. Relaxing this assumption would allow us to extend the model in various ways. First, we could introduce cultural transmission à la Bisin-Verdier (2001) and study the interactions between the endogenous formation of a neighborhood and the incentives to transmit tastes for a particular social norm. Second, Acemoglu and Jackson (2012) studies another evolution process of social norms relying on agents' interpretations

about the past. It would then be worth investigating a model where endogenous urban segregation shapes the information set of individuals and thus influences how history determines the evolution of social norms.

\section{References}

[1] Acemoglu, D. and M. Jackson, 2012, "History, Expectations, and Leadership in the Evolution of Social Norms", forthcoming Review of Economic Studies.

[2] Akerlof, G., 1980, "A Theory of Social Custom of Which Unemployment May Be One Consequence", Quarterly Journal of Economics, vol. 94, 749-775. 
[3] Akerlof, G. and R. Kranton, 2000, "Economics and Identity", Quarterly Journal of Economics, vol. 115, 715-753.

[4] Akerlof, G. and R. Kranton, 2002, "Identity and Schooling: Some Lessons for the Economics of Education", Journal of Economic Literature, vol. 15, 1167-1201.

[5] Anderson, E., 1999, The Code of The Street: Decency, Violence, and the Moral Life of the Inner-City, New York: W.W. Norton \& Company.

[6] Angrist, J., Pathak, P. and Ch. Walters, 2013 "Explaining Charter School Effectiveness", American Economic Journal: Applied Economics, vol. 5, 1-27.

[7] Battu, H., Mwale, M. and Y. Zenou, 2007, "Oppositional Identities and the Labor Market", Journal of Population Economics, vol. 20, 643-667.

[8] Becker, G. and K. Murphy, 2000, Social Economics, Cambridge: Harvard University Press.

[9] Bénabou, R., 1993, "Workings of a City: Location, Education, and Production", Quarterly Journal of Economics, vol. 108, 619-652.

[10] Bénabou, R., 1996a, "Heterogeneity, Stratification and Growth: Macroeconomic Implications of Community Structure and School Finance", American Economic Review, vol. 86, 584-609.

[11] Bénabou, R., 1996b, "Equity and Efficiency in Human Capital Investment: the Local Connection", Review of Economic Studies, vol. 63, 237-264.

[12] Bernheim, D., 1994, "A Theory of Conformity", Journal of Political Economy, vol. 102, 841-877.

[13] Bishop, J.H., 2003, "An Economic Theory of Nerd and Slacker Harassment and its Role in Enforcing Social Norms in Schools", CAHRS Working Paper Series, n²9.

[14] Bishop, J.H., 2004, "Drinking from the Fountain of Knowledge: Student Incentive to Study and Learn-Externalities, Information Problems and Peer Pressure", CAHRS Working Paper Series, $n^{\circ} 19$.

[15] Bisin, A. and Th. Verdier, 2001, "The Economics of Cultural Transmission and the Evolution of Preferences", Journal of Economic Theory, vol. 97, 298-319. 
[16] Bisin, A., Patacchini, E., Verdier, Th. and Y. Zenou, 2011, "Formation and Persistence of Oppositional Identities", European Economic Review, vol. 55, 1046-1071.

[17] Card, D., Mas, A. and J. Rothstein, 2008, "Tipping and the Dynamics of Segregation", Quarterly Journal of Economics, vol. 123, 177-218.

[18] Chetty, A., Hendren, N., Kline, P. and E. Saez, 2014, "Where is the Land of Opportunity? The Geography of Intergenerational Mobility in the United States", NBER Working Paper 19843.

[19] Corneo, G., 1995, "Social Custom, Management Opposition and Trade Union Membership", European Economic Review, vol. 39, 275-292.

[20] Crane, J., 1991, "The Epidemic Theory of Ghettos and Neighborhood Effects on Dropping Out and Teenage Childbearing", American Journal of Sociology, vol. 96, 1226-1259.

[21] Curto, V. and R. Fryer, 2014, "The Potential of Urban Boarding Schools for the Poor: Evidence from SEED", Journal of Labor Economics, forthcoming.

[22] Cutler, D., Glaeser, E. and J. Vigdor, 2008, "When are Ghettos Bad? Lessons from Immigrant Segregation in the United States", Journal of Urban Economics, vol. 63, 759-774.

[23] Durlauf, S., 2004, "Neighborhood Effects", in J. V. Henderson and J. F. Thisse (eds), Handbook of Regional and Urban Economics, Amsterdam: Elsevier Publisher.

[24] Fack, G. and J. Grenet, 2010, "When Do Better Schools Raise Housing Prices? Evidence from Paris Public and Private Schools", Journal of Public Economics, vol. 94, 59-77.

[25] Fordham, S. and J. Ogbu, 1986, "Black Students' School Successes: Coping with the Burden of 'Acting White"', The Urban Review, vol. 18, 176-206.

[26] Fryer, R. and P. Torelli, 2010, "An Empirical Analysis of Acting White", Journal of Public Economics, vol. 94, 380-396.

[27] Galster, G., 2002, "An Economic Efficiency Analysis of Deconcentrating Poverty Populations", Journal of Housing Economics, vol. 11, 303-329.

[28] Galster, G., 2010, "Neighborhood Social Mix: Theory, Evidence, and Implications for Policy and Planning", mimeo. 
[29] Gaviria, A. and S. Raphael, 2001, "School-Based Peer Effects and Juvenile Behavior", The Review of Economics and Statistics, vol. 83, 257-268.

[30] Ioannides, Y., 2013, From Neighborhoods to Nations, Princeton: Princeton University Press.

[31] Kandel, E. and E. Lazear, 1992, "Peer Pressure and Partnerships", Journal of Political Economy, vol. 100, 801-817.

[32] Lamont, M. and M. L. Small, 2008, "How Culture Matters for the Understanding of Poverty: Enriching our Understanding", in L. A. Chih and D. R. Harris (eds), The Colours of Poverty: Why Racial and Ethnic Disparities Exist, New York: Russell Sage Foundation.

[33] Lindbeck, A., Nyberg, S. and J. W. Weibull, 1999, "Social Norms and Economic Incentives in the Welfare State", Quarterly Journal of Economics, vol. 114, 1-35.

[34] Liu, X., Patacchini, E. and Y. Zenou, 2014, "Endogenous Peer Effects: Local Average or Local Aggregate?", Journal of Economic Behavior and Organization, vol. 103, 39-59.

[35] Loury, G., 1977, "A Dynamic Theory of Racial Income Differences", in A. Le Mond (eds), Women, Minorities and Employment Discrimination, Lexington, MA: Lexington Books.

[36] Mas, A. and E. Moretti, 2009, "Peers at Work", American Economic Review, vol. 99, 112-145.

[37] Naylor, R., 1989, "Strikes, Free Riders, And Social Customs", Quarterly Journal of Economics, vol. 104, 771-785.

[38] Reber, S., 2005, "Court-Ordered Desegregation: Successes and Failures Integrating American Schools since Brown versus Board of Education", Journal of Human Resources, vol. 40, 559590.

[39] Tabellini, G., 2008, "The Scope of Cooperation: Values and Incentives", Quarterly Journal of Economics, vol. 123, 905-950.

[40] Topa, G. and Y. Zenou, 2014, "Neighborhood versus Network Effects", in G. Duranton, J. V. Henderson and W. Strange (eds), Handbook of Regional and Urban Economics, Amsterdam: Elsevier Publisher.

[41] Wilson, W.J., 1987, The Truly Disadvantaged: The Inner City, the Urban Underclass and Public Policy, Chicago: University of Chicago Press. 
Date $t$

Date $t+1$

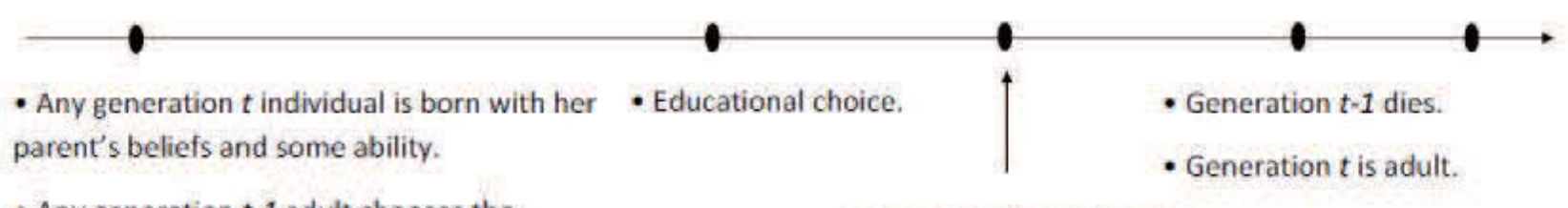

- Any generation $t-1$ adult chooses the family location.

- There are $B_{t}$, respectively $N-B_{t}$,

- Some of the generation

$t$ change their beliefs.

individuals of generation $t$ who are believers,

respectively non-believers.

Figure 1: Timing of events.

\begin{tabular}{|c|c|}
\hline$B$ & \multirow{2}{*}{$N B$} \\
\hline$N B$ & \\
\hline
\end{tabular}

Area 1

Area 2

Figure 2: Two cases of culturally-divided city. On the left, $B_{t} \leq L$, on the right $B_{t}>L$. $B$, respectively $N B$, denotes the believer, respectively non-believer, population. 


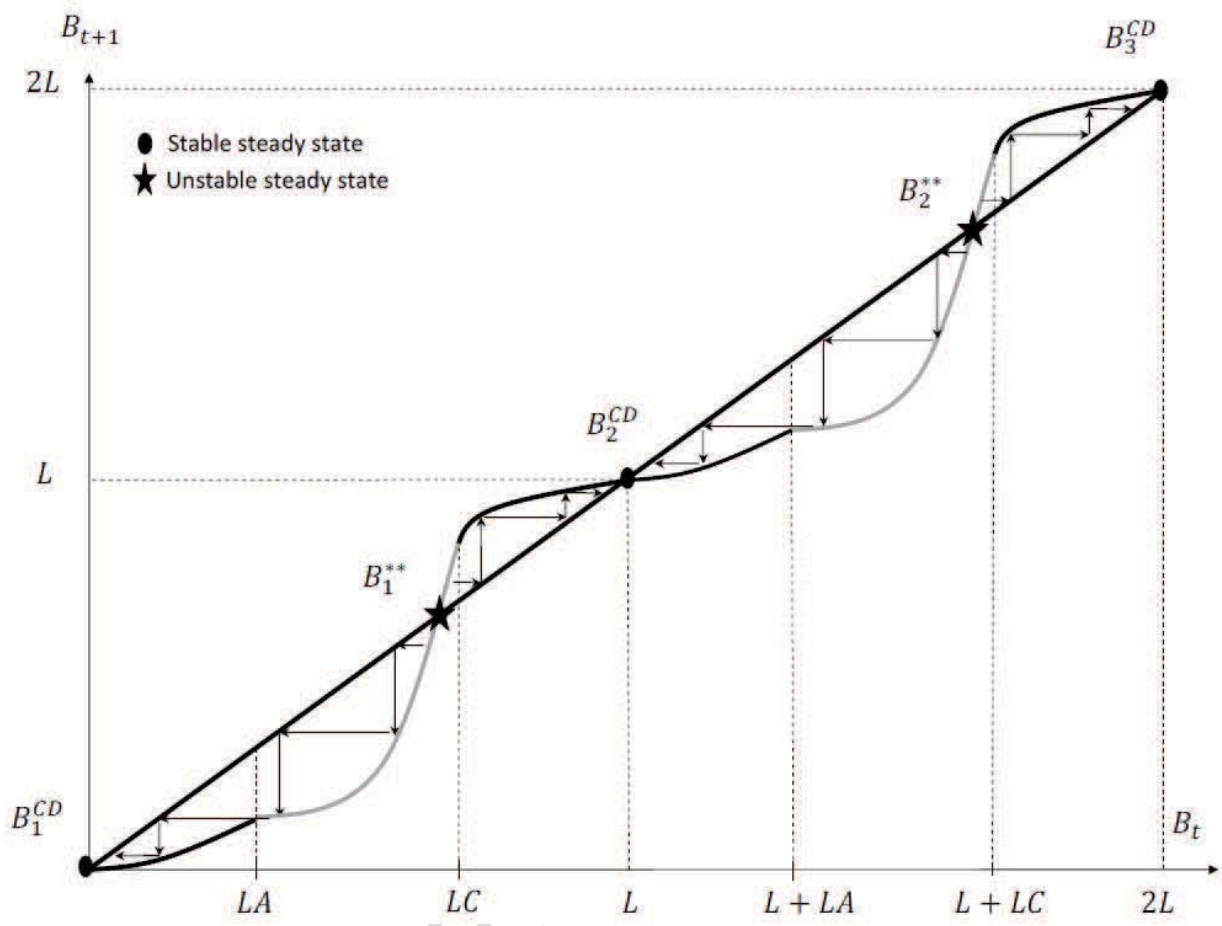

Figure 3: Social norms dynamics in the culturally-divided city.

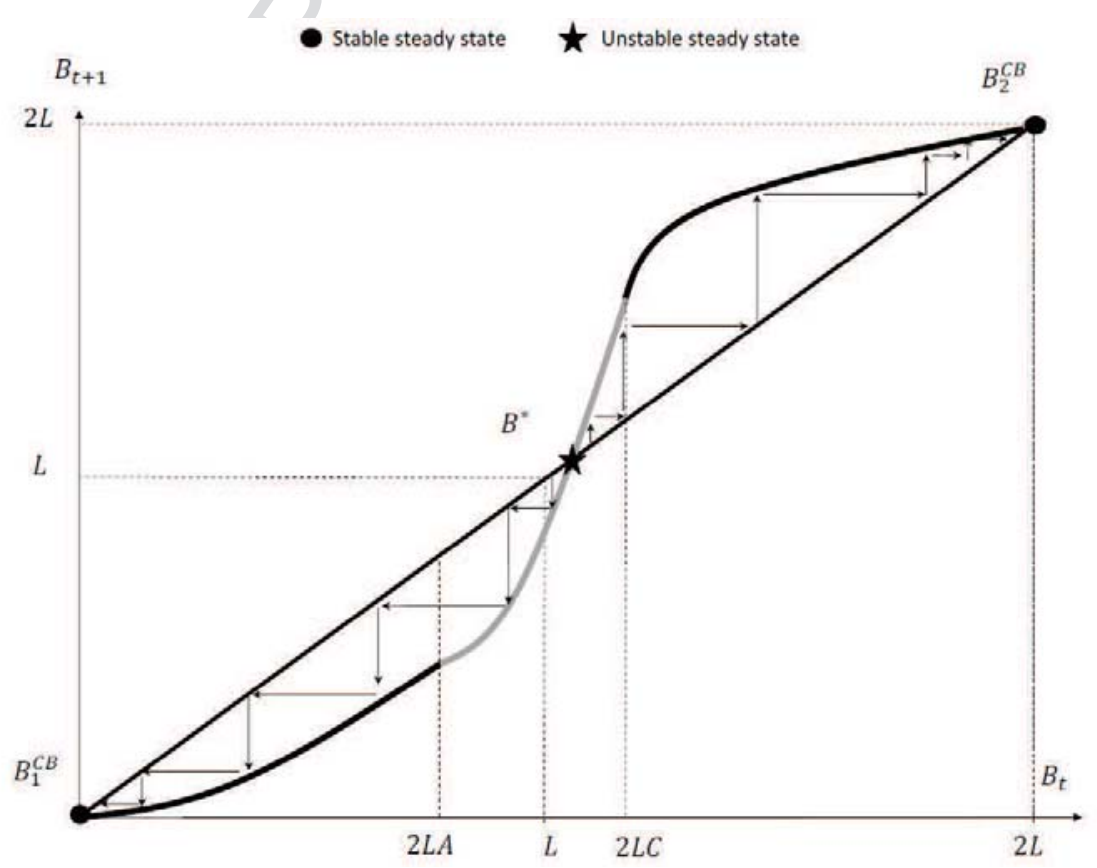

Figure 4: Social norms dynamics in the culturally-balanced city. 


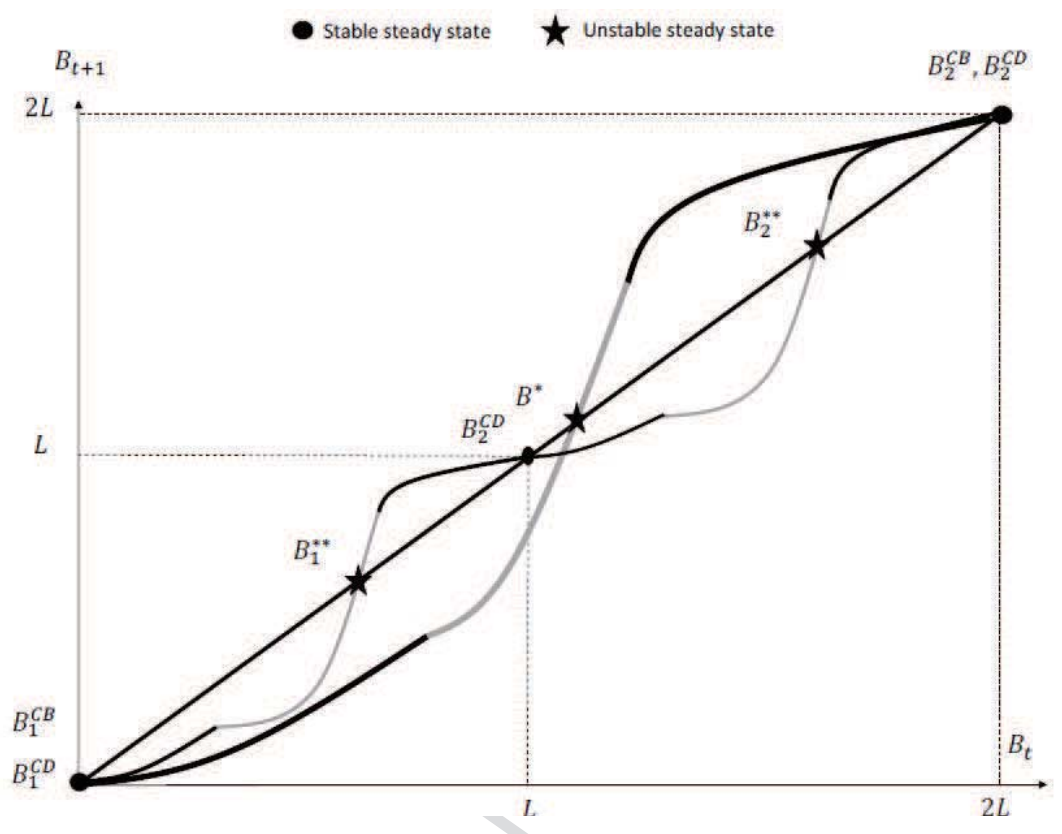

Figure 5: Comparing dynamics under cultural divide and cultural balancedness.

\begin{tabular}{|c|c|c|c|}
\hline$\hat{R}$ & $\tilde{R}$ & $\hat{R}$ & \\
& $\hat{R}$ & $\tilde{R}$ & \\
& $\tilde{P}$ & $\hat{P}$ & \\
& $\tilde{P}$ & $\tilde{P}$ & \\
\hline Area 1 & Area 2 & Area 1 & \\
\hline
\end{tabular}

Figure 6: Two cases of culturally-divided city when $R\left(w_{r}, \widetilde{h}, \rho_{t}, B_{t}\right)>R\left(w_{p}, \widehat{h}, \rho_{t}, B_{t}\right)$ for all $\rho_{t}$ and $B_{t} . \widehat{R}, \widetilde{R}, \widehat{P}, \widetilde{P}$ denote the rich believers, rich non-believers, poor believers, poor non-believers, populations. On the left, $\widehat{N}_{t}^{r} \geq B_{t} / L$ and $\widehat{N}_{t}^{r}+\widetilde{N}_{t}^{r} \geq L$. On the right, $\widetilde{N}_{t}^{p}>L$. 


\begin{tabular}{|c|c|}
\hline$\hat{R}$ & $\tilde{R}$ \\
$\hat{P}$ & $\tilde{P}$ \\
$\tilde{R}$ & \\
\hline
\end{tabular}

Area 1

Area 2

Figure 7: A culturally-divided city when $R\left(w_{r}, \widetilde{h}, \rho_{t}, B_{t}\right)<R\left(w_{p}, \widehat{h}, \rho_{t}, B_{t}\right)$ for all $\rho_{t}$ and $B_{t}$. Population is such that $B_{t}<L$ and $\widetilde{N}_{t}^{p}<L$.

\begin{tabular}{|c|c|}
\hline$\hat{R}$ & $\tilde{R}$ \\
$\hat{P}$ & $\hat{P}$ \\
$\tilde{R}$ & $\tilde{P}$ \\
& \\
\hline Area 1 & Area 2 \\
\hline
\end{tabular}

Figure 8: An urban configuration when bid-rent curves cross more than once. Both poor believers and rich non-believers are indifferent between the two areas. 


\section{Appendix}

\subsection{Proof of Proposition 1}

Proof. Existence. It is always possible to split the believers' population such that $b_{t}^{1}=b_{t}^{2}=$ $B_{t} / 2 L$. According to (11) and (12), we have $\widehat{\rho}\left(B_{t} / 2 L\right)=\widetilde{\rho}\left(B_{t} / 2 L\right)=0$. Hence, no one has an incentive to move.

Stability. Consider the perturbation $\nu>0$ that leads to $b_{t}^{\prime 1}=\left(B_{t}+\nu\right) / 2 L$ and $b_{t}^{\prime 2}=\left(B_{t}-\right.$ $\nu) / 2 L$. Let us consider the case $\widehat{h} \geq \widetilde{h}$. According to (15), we have $\widehat{\rho}\left(\left(B_{t}+\nu\right) / 2 L\right)>\widetilde{\rho}\left(\left(B_{t}+\nu\right) / 2 L\right)$ if and only if $\widehat{h}>\widetilde{h}$ Hence all rich believers migrate to area 1 implying the culturally-balanced equilibrium to be unstable. While we get $\widehat{\rho}\left(\left(B_{t}+\nu\right) / 2 L\right)<\widetilde{\rho}\left(\left(B_{t}+\nu\right) / 2 L\right)$ if and only if $\widehat{h}<\widetilde{h}$, implying that non-believers migrate to area 1 , thus restoring the culturally-balanced equilibrium.

\subsection{Proof of Proposition 2}

Proof. According to (15), we have

$$
\left.\left.\widehat{\rho}\left(b_{t}^{1}\right)>\widetilde{\rho}\left(b_{t}^{1}\right) \text { for any } b_{t}^{1} \in\right] B_{t} / 2 L, \min \left\{B_{t} / L, 1\right\}\right] \text { if and only if } \widehat{h}>\widetilde{h} .
$$

Hence, when $\rho_{t}=\widehat{\rho}\left(\min \left\{B_{t} / L, 1\right\}\right)$ nobody has an incentive to move. The duple $\left[\widehat{\rho}\left(\min \left\{B_{t} / L, 1\right\}\right), b_{t}^{1}=\right.$ $\left.\min \left\{B_{t} / L, 1\right\}\right]$ is thus an equilibrium. Whatever the small perturbation of the area 1 population, believers still strictly prefer to live in urban area 1 . This equilibrium is stable.

\subsection{Proof of Proposition 3}

Proof. From (6)-(8) and (16), the dynamics of a culturally-divided equilibrium are characterized as follows:

$$
\begin{aligned}
& \int \frac{(\Delta u) B_{t}+\frac{B_{t}^{2}}{L}(2 \widehat{h})}{c} \text { when } B_{t} \in[0, L A] \\
& B_{t+1}^{\star \star}=\left\{\begin{array}{c}
\frac{B_{t}^{2}}{L} \frac{2 \Delta h}{c}+B_{t} \frac{4 \widetilde{h}}{c}+L\left(\frac{\Delta u-(2 \widetilde{h})}{c}\right) \text { when } B_{t} \in[L A, L C] \\
-\frac{B_{t}^{2}}{L} \frac{(2 \widetilde{h})}{c}+B_{t}\left(1-\frac{\Delta u}{c}+\frac{4 \widetilde{h}}{c}\right)+L\left(\frac{\Delta u-2 \widetilde{h}}{c}\right) \text { when } B_{t} \in[L C, L] \\
\frac{B_{t}^{2}}{L} \frac{2 \widehat{h}}{c}+B_{t}\left(\frac{\Delta u-4 \widehat{h}}{c}\right)+L \frac{(2 \widehat{h})-\Delta u}{c}+L \text { when } B_{t} \in[L, L+L A]
\end{array}\right. \\
& \frac{B_{t}^{2}}{L} \frac{2 \Delta h}{c}+2 B_{t}\left(\frac{2 \widetilde{h}-2 \Delta h}{c}\right)+L\left(\frac{2 \Delta h}{c}-\frac{6 \widetilde{h}}{c}+\frac{\Delta u}{c}+1\right) \text { when } B_{t} \in[L+L A, L+L C] \\
& -\frac{B_{t}^{2}}{L} \frac{2 \widetilde{h}}{c}+B_{t}\left(1-\frac{\Delta u}{c}+\frac{8 \widetilde{h}}{c}\right)+L\left(\frac{2 \Delta u-8 \widetilde{h}}{c}\right) \text { when } B_{t} \in[L+L C, 2 L] .
\end{aligned}
$$

$B_{t+1}^{\star \star}\left(B_{t}\right)$ is a continuous function of $B_{t}$. It is easy to check that $B_{t+1}^{\star \star}\left(B_{t}\right)$ is increasing over $[0,2 L]$. Further, $B_{t+1}^{\star \star}(0)=0$. From Assumption 2, we know that $B_{t+1}^{\star \star \prime}(0)=\Delta u / c<1$. Hence, 
$\lim _{B_{t} \rightarrow 0^{+}}\left(B_{t+1}^{\star \star}\left(B_{t}\right)-B_{t}\right)<0$. We have $B_{t+1}^{\star \star}(L)=L$. From Assumption 2, we have $0<\lim _{B_{t} \rightarrow L^{-}} B_{t+1}^{\star \star \prime}\left(B_{t}\right)=$ $1-(\Delta u / c)<1$ and $0<\lim _{B_{t} \rightarrow L^{+}} B_{t+1}^{\star \star \prime}\left(B_{t}\right)=\Delta u / c<1$. Hence, $B_{t+1}^{\star \star}\left(B_{t}\right)$ must cross the $45^{\circ}$ line at $B_{t}=L$ from above, formally we must have $\lim _{B_{t} \rightarrow L^{-}}\left(B_{t+1}^{\star \star}\left(B_{t}\right)-B_{t}\right)>0$ and $\lim _{B_{t} \rightarrow L^{+}}\left(B_{t+1}^{\star \star}\left(B_{t}\right)-B_{t}\right)<$ 0 . We have $B_{t+1}^{\star \star}(2 L)=2 L$. From Assumption 2, we know that $0<B_{t+1}^{\star \star}(2 L)=1-(\Delta u / c)<1$. Hence, $B_{t+1}^{\star \star}\left(B_{t}\right)$ must cross the $45^{\circ}$ line at $B_{t}=2 L$ from above, formally $\lim _{B_{t} \rightarrow 2 L}\left(B_{t+1}^{\star \star}\left(B_{t}\right)-B_{t}\right)>$ 0. As $B_{t+1}^{\star \star}(0)=0, \lim _{B_{t} \rightarrow 0^{+}}\left(B_{t+1}^{\star \star}\left(B_{t}\right)-B_{t}\right)<0$, and given that $B_{t+1}^{\star \star}$ crosses twice the the $45^{\circ}$ line from above at $B_{t}=L$ and $B_{t}=2 L$, it must also cross twice the $45^{\circ}$ line from below. We deduce that there exist $B_{1}^{\star \star}$ and $B_{2}^{\star \star}$ with $0<B_{1}^{\star \star}<L<B_{2}^{\star \star}<2 L$ such that $B_{t+1}^{\star \star}\left(B_{1}^{\star \star}\right)=B_{1}^{\star \star}$ and $B_{t+1}^{\star \star}\left(B_{2}^{\star \star}\right)=B_{2}^{\star \star}$.

Furthermore, we can provide some information about $B_{1}^{\star \star}$ and $B_{2}^{\star \star}$ :

(i) We have $B_{1}^{\star \star}>L A$ and $B_{2}^{\star \star}>L+L A$. It amounts to show that $B_{t+1}^{\star \star}(L A)<L A$ which is equivalent to $B_{t+1}^{\star \star}(L+L A)<L+L A$. Hence, $B_{t+1}^{\star \star}(L A)<L A$ can be written as follows

$$
\frac{\Delta u}{c}+\frac{A(2 \widehat{h})}{c}<1
$$

Given that $A \equiv 1-(\Delta u / 2 \widetilde{h})$ we have

$$
\frac{\Delta u}{c}+\left(\frac{2 \widehat{h}}{c}-\frac{\Delta u}{2 \widetilde{h}} * \frac{(2 \widehat{h})}{c}\right)<1
$$

which is equivalent to

$$
\frac{\Delta u}{c}\left(1-\frac{\widehat{h}}{\widetilde{h}}\right)+\left(\frac{2 \widehat{h}}{c}\right)<1
$$

which can be written as

$$
\frac{1}{\frac{\Delta u}{c}\left(-\frac{\Delta h}{\widetilde{h}}\right)+\left(\frac{2 \widehat{h}}{c}\right)}>1 .
$$

Multiplying both the numerator and denominator of the LHS of this inequality by $c / 2 \widehat{h}$ leads to

$$
\frac{\frac{c}{2 \widehat{h}}}{\frac{\Delta u}{(2 \widehat{h})}\left(-\frac{\Delta h}{\widetilde{h}}\right)+1}>1
$$

which is equivalent to

$$
\frac{c}{2 \widehat{h}}-\frac{\Delta u}{2 \widehat{h}}>1-\frac{\Delta u}{2 \widetilde{h}}
$$

which is Assumption 3. Hence, the result.

(ii) If $B_{t+1}^{\star \star}(L C) \geq L C \Leftrightarrow B_{t+1}^{\star \star}(L+L C) \geq L+L C \Leftrightarrow(C)^{2} L \frac{2 \Delta h}{c}+C L \frac{4 \widetilde{h}}{c}+L\left(\frac{\Delta u-2 \widetilde{h}}{c}\right) \geq L C$ then $L A \leq B_{1}^{\star \star} \leq L C$ and that $L A+L \leq B_{2}^{\star \star} \leq L C+L$.

(iii) If $B_{t+1}^{\star \star}(L C)<L C \Leftrightarrow B_{t+1}^{\star \star}(L+L C) \geq L+L C \Leftrightarrow(C)^{2} L \frac{2 \Delta h}{c}+C L \frac{4 \widetilde{h}}{c}+L\left(\frac{\Delta u-2 \widetilde{h}}{c}\right)<L C$ then $L C \leq B_{1}^{\star \star} \leq L$ and $L C+L \leq B_{2}^{\star \star} \leq 2 L$. 


\subsection{Proof of Proposition 4}

Proof. From (6)-(8), the rate of education in a culturally-balanced equilibrium equals at each date $t$

$$
\lambda_{t}\left(\frac{B_{t}}{2 L}\right)=\left\{\begin{array}{c}
\frac{(\Delta u) \frac{B_{t}}{2 L}+\left(\frac{B_{t}}{2 L}\right)^{2}(2 \widehat{h})}{c} \text { when } 0 \leq B_{t} \leq 2 L A \\
\left(\frac{B_{t}}{2 L}\right)^{2} \frac{2 \Delta h}{c}+\frac{B_{t}}{L} \frac{2 \widetilde{h}}{c}-\frac{(2 \widetilde{h})}{c}+\frac{\Delta u}{c} \text { when } 2 L A \leq B_{t} \leq 2 L C \\
-\left(\frac{B_{t}}{2 L}\right)^{2} \frac{(2 \widetilde{h})}{c}+\frac{B_{t}}{2 L}\left(1-\frac{\Delta u}{c}+\frac{4 \widetilde{h}}{c}\right)+\frac{\Delta u-2 \widetilde{h}}{c} \text { when } 2 L C \leq B_{t} \leq 2 L
\end{array}\right.
$$

Hence, from (16), we have

$$
B_{t+1}^{*}=\left\{\begin{array}{c}
B_{t}^{2} \frac{1}{L} \frac{\widehat{h}}{c}+B_{t} \frac{(\Delta u)}{c} \text { when } 0 \leq B_{t} \leq 2 L A \\
B_{t}^{2} \frac{1}{L} \frac{\Delta h}{c}+B_{t} \frac{4 \widetilde{h}}{c}+2 L\left(\frac{\Delta u-2 \widetilde{h}}{c}\right) \text { when } 2 L A \leq B_{t} \leq 2 L C \\
-B_{t}^{2} \frac{1}{L} \frac{\widetilde{h}}{c}+B_{t}\left(1-\frac{\Delta u}{c}+\frac{4 \widetilde{h}}{c}\right)+2 L\left(\frac{\Delta u-2 \widetilde{h}}{c}\right) \text { when } 2 L C \leq B_{t} \leq 2 L .
\end{array}\right.
$$

$B_{t+1}^{\star}\left(B_{t}\right)$ is a continuous function of $B_{t}$. It is easy to check that $B_{t+1}^{\star}\left(B_{t}\right)$ is increasing over $[0,2 L]$. Further, $B_{t+1}^{\star}(0)=0$. From Assumption 2, we know that $B_{t+1}^{\star \prime}(0)=\Delta u / c<1$. Hence, $\lim _{B_{t} \rightarrow 0^{+}}\left(B_{t+1}^{\star}\left(B_{t}\right)-B_{t}\right)<0$. We have $B_{t+1}^{\star}(2 L)=2 L$. From Assumption 2, we know that $0<$ $B_{t+1}^{\star \prime}(2 L)=1-(\Delta u / c)<1$. Hence, $B_{t+1}^{\star}\left(B_{t}\right)$ must cross the $45^{\circ}$ line from above at $B_{t}=2 L$, formally $\lim _{B_{t} \rightarrow 2 L^{-}}\left(B_{t+1}^{\star}\left(B_{t}\right)-B_{t}\right)>0$. As $B_{t+1}^{\star}(0)=0, \lim _{B_{t} \rightarrow 0^{+}}\left(B_{t+1}^{\star}\left(B_{t}\right)-B_{t}\right)<0$ and $B_{t+1}^{\star}\left(B_{t}\right)$ must cross the $45^{\circ}$ line from above at $B_{t}=2 L$, it is easy to deduce that $B_{t+1}^{\star}\left(B_{t}\right)$ must cross the $45^{\circ}$ line from below once. Hence, there exists $0<B^{\star}<2 L$ such that $B_{t+1}^{\star}\left(B^{\star}\right)=B^{\star}$.

Let us provide information on $B^{\star}$ :

(i) We can first show that $B^{\star}>2 L A$. This amounts to show that $B_{t+1}^{\star}\left(B_{t}\right)<B_{t}$ for $B_{t} \in$ $[0,2 L A]$. Hence, this inequality is equivalent to

$$
\frac{\Delta u+B_{t}(2 \widehat{h})}{c}<1
$$

For $B_{t}=2 L A$, we have

$$
\frac{\Delta u}{c}+\frac{A(2 \widehat{h})}{c}<1
$$

Given that $A \equiv 1-(\Delta u / 2 \widetilde{h})$ we have

$$
\frac{\Delta u}{c}+\left(\frac{2 \widehat{h}}{c}-\frac{\Delta u}{\widetilde{h}} * \frac{\widehat{h}}{c}\right)<1
$$

which is equivalent to

$$
\frac{\Delta u}{c}\left(1-\frac{\widehat{h}}{\widetilde{h}}\right)+\left(\frac{2 \widehat{h}}{c}\right)<1
$$


which can be written as follows

$$
\frac{1}{\frac{\Delta u}{c}\left(-\frac{\Delta h}{\widetilde{h}}\right)+\left(\frac{2 \widehat{h}}{c}\right)}>1 .
$$

Multiplying both the numerator and denominator of the LHS of this inequality by $c / 2 \widehat{h}$ leads to

$$
\frac{\frac{c}{2 \widehat{h}}}{\frac{\Delta u}{(2 \widehat{h})}\left(-\frac{\Delta h}{\widetilde{h}}\right)+1}>1
$$

which is equivalent to

$$
\frac{c}{2 \widehat{h}}-\frac{\Delta u}{2 \widehat{h}}>1-\frac{\Delta u}{2 \widetilde{h}}
$$

which is Assumption 3. Hence, the result.

(ii) If $B_{t+1}^{\star}(2 L A) \leq 2 L A \Leftrightarrow(\Delta u+A 2 \widehat{h}) / c \leq 1$ and $B_{t+1}^{\star}(2 L C)>2 L C \Leftrightarrow(C)^{2} L(2 \Delta h / c)+$ $C L(4 \widetilde{h} / c)+L((\Delta u-2 \widetilde{h}) / c) \geq L C$ then $2 L A \leq B^{\star} \leq 2 L C$. Considering item (ii) of Proof of Proposition 3, we can see that when $L A \leq B_{1}^{\star \star} \leq L C$ and that $L A+L \leq B_{2}^{\star \star} \leq L C+L$ we also have $2 L A \leq B^{\star} \leq 2 L C$.

(iii) If $B_{t+1}^{\star}(2 L C) \leq 2 L C \Leftrightarrow(C)^{2} L(2 \Delta h / c)+C L(4 \widetilde{h} / c)+L((\Delta u-2 \widetilde{h}) / c)<L C$ then $2 L C \leq$ $B^{\star} \leq 2 L$. Considering item (iii) of Proof of Proposition 3, we can see that when $L C \leq B_{1}^{\star \star} \leq L$ and $L C+L \leq B_{2}^{\star \star} \leq 2 L$ we also have $2 L C \leq B^{\star} \leq 2 L$.

\subsection{Comparing Social Dynamics under cultural divide and cultural integration}

We offer the following

Proposition 6 (i) When $B_{1}^{\star \star} \in[L A, L C]$ and $B_{2}^{\star \star} \in[L A+L, L C+L]$, we have $B^{\star} \in[2 L A, 2 L C]$ and $B_{1}^{\star \star} \leq B^{\star} \leq B_{2}^{\star \star}$.

(ii) When $B_{1}^{\star \star} \in[L C, L]$ and $B_{2}^{\star \star} \in[L C+L, 2 L]$, we have $B^{\star} \in[2 L C, 2 L]$ with

$$
\begin{aligned}
B^{\star} & \leq B_{2}^{\star \star} \text { and, } \\
\text { if } 2(c-\Delta u) /(2 \widehat{h}) & >1 \text { then } B_{1}^{\star \star}<B^{\star}, \\
\text { otherwise } B_{1}^{\star \star} & \lesseqgtr B^{\star} \\
& \Longleftrightarrow L\left(-3\left(\frac{(2 \widetilde{h})}{c}-\frac{\Delta u}{c}\right)+\left(\sqrt{2\left(1-\frac{\Delta u}{2 \widetilde{h}}\right)}\right)\left(\left(\frac{4 \widetilde{h}}{c}-\frac{\Delta u}{c}\right)\right)\right) \gtreqless 0 .
\end{aligned}
$$

Proof. We already know that when $B_{1}^{\star \star} \in[L A, L C]$ and $B_{2}^{\star \star} \in[L A+L, L C+L]$, respectively $B_{1}^{\star \star} \in[L C, L]$ and $B_{2}^{\star \star} \in[L C+L, 2 L]$, we have $B^{\star} \in[2 L A, 2 L C]$, respectively $B^{\star} \in[2 L C, 2 L]$. 
(i) Let us show that $B^{\star}>B_{1}^{\star \star}$ when $B_{1}^{\star \star} \in[L A, L C]$ and $B^{\star} \in[2 L A, 2 L C]$. If $2 L A>L C$, it is obvious that $B^{\star}>B_{1}^{\star \star}$. If $2 L A<L C$, we are going to show that

$$
B_{t+1}^{\star \star}\left(B_{t}\right)>B_{t+1}^{\star}\left(B_{t}\right) \text { for any } B_{t} \in[L A, L C] \cap[2 L A, 2 L C] .
$$

We have

$$
B_{t+1}^{\star \star}\left(B_{t}\right)-B_{t+1}^{\star}\left(B_{t}\right)=\frac{B_{t}^{2}}{L} \frac{\Delta h}{c}-L\left(\frac{\Delta u-2 \tilde{h}}{c}\right)
$$

According to Assumption 2, we have $\Delta u<2 \tilde{h}$, we thus deduce that $B_{t+1}^{\star \star}\left(B_{t}\right)-B_{t+1}^{\star}\left(B_{t}\right)>0$. This implies that $B_{t+1}^{\star}($.$) intersects the 45^{\circ}$ line before $B_{t+1}^{\star}($.$) .$

Let us consider the case $B_{1}^{\star \star} \in[L C, L]$ and $B^{\star} \in[2 L C, 2 L]$. If $2 C>1$, it is obvious that $B^{\star}>B_{1}^{\star \star}$. If $2 C<1$, we are going to study for any $B_{t} \in[L C, L] \cap[2 L C, 2 L]$

$$
B_{t+1}^{\star \star}\left(B_{t}\right)-B_{t+1}^{\star}\left(B_{t}\right)=-\frac{B_{t}^{2}}{L} \frac{\widetilde{h}}{c}-L\left(\frac{\Delta u-2 \widetilde{h}}{c}\right)
$$

As $\Delta u-2 \widetilde{h}<0$ given Assumption 2, we have

$$
B_{t+1}^{\star \star}\left(B_{t}\right) \lesseqgtr B_{t+1}^{\star}\left(B_{t}\right) \text { if and only if } L(2 \widetilde{h}-\Delta u) \lesseqgtr \frac{B_{t}^{2}}{L} \widetilde{h}
$$

which is equivalent to

$$
B_{t+1}^{\star \star}\left(B_{t}\right) \lesseqgtr B_{t+1}^{\star}\left(B_{t}\right) \text { if and only if } L \sqrt{2\left(1-\frac{\Delta u}{2 \widetilde{h}}\right)} \lesseqgtr B_{t} .
$$

We will thus have

$$
B_{1}^{\star \star} \lesseqgtr B^{\star} \text { if and only if } B_{t+1}^{\star \star}\left(L \sqrt{2\left(1-\frac{\Delta u}{2 \widetilde{h}}\right)}\right) \gtreqless L \sqrt{2\left(1-\frac{\Delta u}{2 \widetilde{h}}\right)}
$$

which is equivalent to

$$
B_{1}^{\star \star} \lesseqgtr B^{\star} \text { if and only if } L\left(-3\left(\frac{2 \widetilde{h}}{c}-\frac{\Delta u}{c}\right)+\left(\sqrt{2\left(1-\frac{\Delta u}{2 \widetilde{h}}\right)}\right)\left(\left(\frac{4 \widetilde{h}}{c}-\frac{\Delta u}{c}\right)\right)\right) \gtreqless 0 .
$$

(iii) Let us consider the case $B_{2}^{\star \star} \in[L A+L, L C+L]$ and $B^{\star} \in[2 L A, 2 L C]$ and let us show that $B^{\star}<B_{2}^{\star \star}$. If $2 L C<L A+L$, it is obvious that $B^{\star}<B_{2}^{\star \star}$. If $2 L C>L A+L$, we are going to show that

$$
B_{t+1}^{\star}\left(B_{t}\right)>B_{t+1}^{\star \star}\left(B_{t}\right) \text { for any } B_{t} \in[L A+L, L C+L] \cap[2 L A, 2 L C] .
$$

We have

$$
B_{t+1}^{\star}\left(B_{t}\right)-B_{t+1}^{\star \star}\left(B_{t}\right)=-B_{t}^{2} \frac{1}{L} \frac{\Delta h}{c}+4 B_{t} \frac{\Delta h}{c}+L\left(\frac{\Delta u+2 \widetilde{h}-2 \Delta h}{c}-1\right)>0
$$


The above function has its maximum in $B_{t}=L$ and we have

$$
\begin{aligned}
B_{t+1}^{\star}(2 L C)-B_{t+1}^{\star \star}(2 L C) & =4 L \frac{\Delta h}{c}+L\left(\frac{\Delta u+2 \widetilde{h}-2 \Delta h}{c}-1\right) \\
& =L\left(\frac{2 \widehat{h}-(c-\Delta u)}{c}\right) .
\end{aligned}
$$

According to Assumption $2(c-\Delta u) /(2 \widehat{h})<1$, hence $B_{t+1}^{\star}(2 L C)-B_{t+1}^{\star \star}(2 L C)>0$. Hence, $B_{t+1}^{\star}\left(B_{t}\right)>B_{t+1}^{\star \star}\left(B_{t}\right)$ for any $B_{t} \in[L A+L, L C+L] \cap[2 L A, 2 L C]$ implying that $B_{t+1}^{\star}($.$) in-$ tersects the $45^{\circ}$ line before $B_{t+1}^{\star \star}($.$) and that B^{\star}<B_{2}^{\star \star}$. Let us now consider the case where $B_{2}^{\star \star} \in[L C+L, 2 L]$ and $B^{\star} \in[2 L C, 2 L]$ and let us show that $B^{\star}<B_{2}^{\star \star}$. We are going to show that

$$
B_{t+1}^{\star}\left(B_{t}\right)>B_{t+1}^{\star \star}\left(B_{t}\right) \text { for any } B_{t} \in[L C+L, 2 L] \cap[2 L C, 2 L] .
$$

We have

$$
\begin{aligned}
B_{t+1}^{\star}\left(B_{t}\right)-B_{t+1}^{\star \star}\left(B_{t}\right) & =\frac{B_{t}^{2}}{L} \frac{\widetilde{h}}{c}-B_{t} \frac{4 \widetilde{h}}{c}+4 L \frac{\widetilde{h}}{c} \\
& =\frac{2 \widetilde{h}}{c}\left(\frac{B_{t}}{\sqrt{2 L}}-\sqrt{2 L}\right)^{2}>0 .
\end{aligned}
$$

Hence, $B_{t+1}^{\star}($.$) intersects the 45^{\circ}$ line before $B_{t+1}^{\star \star}($.$) and B_{2}^{\star \star}>B^{\star}$.

\subsection{Proof of Proposition 5}

We skip the Proof of item (i) as it is formally equivalent to the Proof of Proposition 1. Let us mention that stability of the culturally-balanced equilibrium arises if $R\left(w_{z}, \widehat{h}, 0, B_{t}\right)<R\left(w_{z}, \widetilde{h}, 0, B_{t}\right)$ for $z=r, p$. We denote by $\widehat{N}_{t}^{z}\left(\widehat{N}_{t}^{z, j}\right)$, respectively $\widetilde{N}_{t}^{z}\left(\widetilde{N}_{t}^{z, j}\right)$, the number of parents with income $w_{z}$ who are believers, respectively non-believers, in the whole population (in area $j$ ). A formal equivalent of item (ii) of Proposition 5 is given by both following propositions:

Proposition 7 Consider that $(\widehat{h}-\widetilde{h})(\Delta w+\Delta u-(c / 2)) \geq 0$ implying that $R\left(w_{z}, \widehat{h}, \rho_{t}, B_{t}\right)>$ $R\left(w_{z}, \widetilde{h}, \rho_{t}, B_{t}\right)$ for $z=r, p$, any $\rho_{t}<w_{p}$ and $B_{t}$. At any date $t$, we have the following results

1. If $\widehat{N}_{t}^{r} \geq L$ then the equilibrium $\left[\rho_{t}^{*}=\widehat{\rho}^{r}(1), b_{t}^{1 *}=1\right]$ exists and it is stable.

2. If $\widehat{N}_{t}^{r}<L$, then we have the following results

2.a) If $R\left(w_{r}, \widetilde{h}, \rho_{t}, B_{t}\right)>R\left(w_{p}, \widehat{h}, \rho_{t}, B_{t}\right)$ for all $\rho$ and $B_{t}$ then

(i) the equilibrium $\left[\rho_{t}^{*}=\widetilde{\rho}^{r}\left(\widehat{N}_{t}^{r} / L\right), b_{t}^{1 *}=\widehat{N}_{t}^{r} / L\right]$ exists if $\widehat{N}_{t}^{r} \geq B_{t} / 2$ and $\widetilde{N}_{t}^{r}+\widehat{N}_{t}^{r}>$ L. It is stable. 
(ii) the equilibrium $\left[\rho_{t}^{*}=\widehat{\rho}^{p}\left(\left(L-\widetilde{N}_{t}^{r}\right) / L\right), b_{t}^{1 *}=\left(L-\widetilde{N}_{t}^{r}\right) / L\right]$ exists if $L-\widetilde{N}_{t}^{r}>B_{t} / 2$ and $\widetilde{N}_{t}^{r}+\widehat{N}_{t}^{r}<$ L. It is stable.

(iii) the equilibrium $\left[\rho_{t}^{*}=\widetilde{\rho}^{p}\left(B_{t} / L\right), b_{t}^{1 *}=B_{t} / L\right]$ exists if $\widetilde{N}_{t}^{p}>L$.

2.b) If $R\left(w_{p}, \widehat{h}, \rho_{t}, B_{t}\right)>R\left(w_{r}, \widetilde{h}, \rho_{t}, B_{t}\right)$ for all $\rho$ and $B_{t}$ then,

(i) the equilibrium $\left[\rho_{t}^{*}=\widehat{\rho}^{p}(1), b_{t}^{1 *}=1\right]$ exists if $B_{t} \geq L$. It is stable,

(ii) the equilibrium $\left[\rho_{t}^{*}=\widetilde{\rho}^{r}\left(B_{t} / L\right), b_{t}^{1 *}=B_{t} / L\right]$ exists if $B_{t}<L$ and $\widetilde{N}_{t}^{p}<L$. It is stable.

(iii) the equilibrium $\left[\rho_{t}^{*}=\widetilde{\rho}^{p}\left(B_{t} / L\right), b_{t}^{1 *}=B_{t} / L\right]$ exists if $B_{t}<L$ and $\widetilde{N}_{t}^{p}>L$. It is stable.

2.c) If there exists some $b_{t} \in\left[B_{t} / 2 L, 1\right]$ such that $\widetilde{\rho}^{r}(b)=\widehat{\rho}^{p}(b), L=\widehat{N}_{t}^{r}+\widehat{N}_{t}^{p, 1}+\widetilde{N}_{t}^{r, 1}=$ $\widehat{N}_{t}^{p, 2}+\widetilde{N}_{t}^{r, 2}+\widetilde{N}_{t}^{p}$ with $\widehat{N}_{t}^{w_{r}}+\widehat{N}_{t}^{p, 1}>\widehat{N}_{t}^{p, 2}$ then the equilibrium $\left[\rho^{*}=\widetilde{\rho}^{r}\left(b_{t}\right)=\widehat{\rho}^{p}\left(b_{t}\right), b_{t}^{1 *}=b_{t}\right]$ exists. It is stable if and only if $R\left(w_{r}, \widetilde{h}, \rho_{t}^{*}, B_{t}\right)-R\left(w_{p}, \widehat{h}, \rho_{t}^{*}, B_{t}\right)>0$.

Proposition 8 Consider that $R\left(w_{z}, \widehat{h}, \rho_{t}, B_{t}\right)<R\left(w_{z}, \widetilde{h}, \rho_{t}, B_{t}\right)$ for $z=r, p$ implied by either $\Delta w+\Delta u-(c / 2)>0, \widehat{h}<\widetilde{h}$ and $(\widehat{h}-\widetilde{h})(\Delta w+\Delta u-(c / 2))+4 \widetilde{h}^{2}<0$ or $\Delta w+\Delta u-(c / 2)<0$, $\widehat{h}>\widetilde{h}$ and $(\widehat{h}-\widetilde{h})(\Delta w+\Delta u-(c / 2)+4(\widehat{h}+\widetilde{h}))+4 \widetilde{h}^{2}<0$. At any date $t$, we have the following results

1. If $R\left(w_{r}, \widehat{h}, \rho_{t}, B_{t}\right)<R\left(w_{p}, \widetilde{h}, \rho_{t}, B_{t}\right)$ for all $\rho_{t}, B_{t}$, no culturally-divided equilibrium exists.

2. If $R\left(w_{r}, \widehat{h}, \rho_{t}, B_{t}\right)>R\left(w_{p}, \widetilde{h}, \rho_{t}, B_{t}\right)$ for all $\rho_{t}, B_{t}$ then

(i) the equilibrium $\left[\rho_{t}=\widehat{\rho}_{t}^{r}\left(\widehat{N}_{t}^{r, 1} / L\right), b_{t}^{1}=\widehat{N}_{t}^{r, 1} / L\right]$ exists if $L-\widetilde{N}_{t}^{r}=\widehat{N}_{t}^{r, 1}>B_{t} / 2$. It is stable.

(ii) the equilibrium $\left[\rho_{t}=\widetilde{\rho}_{t}^{p}\left(\widehat{N}_{t}^{r} / L\right), b_{t}^{1}=\widehat{N}_{t}^{r} / L\right]$ exists if $\widehat{N}_{t}^{r}>B_{t} / 2, \widetilde{N}_{t}^{r}+\widehat{N}_{t}^{r}<L$ and $\widetilde{N}_{t}^{r}+\widehat{N}_{t}^{r}+\widetilde{N}_{t}^{p}>$ L. It is stable.

Proof. Let us first consider Proposition 7.

Case 1. When $\widehat{N}_{t}^{r} \geq L$, we consider the urban configuration such that urban area 1 is inhabited by only rich believers. It turns out that $b_{t}^{1}=1>b_{t}^{2}$. Given that $R\left(w_{z}, \widehat{h}, \rho_{t}, B_{t}\right)>R\left(w_{z}, \widetilde{h}, \rho_{t}, B_{t}\right)$ for $z=r, p$, any $\rho_{t}$ and $B_{t}$, with $\rho=\widehat{\rho}^{r}(1)$, we have:

$$
\begin{aligned}
& u\left(w_{r}\right)-u\left(w_{r}-\widehat{\rho}^{r}(1)\right)=a\left(\frac{2-\left(B_{t} / L\right)}{c}\right)(2 \widehat{h})\left(\Delta w+\Delta u+2 \widehat{h} \frac{B_{t}}{L}-\frac{c}{2}\right) \\
& u\left(w_{r}\right)-u\left(w_{r}-\widehat{\rho}^{r}(1)\right)>a\left(\frac{2-\left(B_{t} / L\right)}{c}\right)(2 \widetilde{h})\left(\Delta w+\Delta u-2 \widetilde{h}\left(2-\frac{B_{t}}{L}\right)-\frac{c}{2}\right) \\
& u\left(w_{p}\right)-u\left(w_{p}-\widehat{\rho}^{r}(1)\right)>a\left(\frac{2-\left(B_{t} / L\right)}{c}\right)(2 \widehat{h})\left(\Delta w+\Delta u+2 \widehat{h} \frac{B_{t}}{L}-\frac{c}{2}\right) \\
& u\left(w_{p}\right)-u\left(w_{p}-\widehat{\rho}^{r}(1)\right)>a\left(\frac{2-\left(B_{t} / L\right)}{c}\right)(2 \widetilde{h})\left(\Delta w+\Delta u-2 \widetilde{h}\left(2-\frac{B_{t}}{L}\right)-\frac{c}{2}\right) .
\end{aligned}
$$


The duple $\left[\widehat{\rho}^{r}(1), b_{t}^{1}=1\right]$ is an equilibrium as nobody has an incentive to move. Further, whatever the small perturbation of the equilibrium (immigration of individuals $\widetilde{N}^{r}$ or $\widehat{N}^{p}$ or also $\widetilde{N}^{p}$ in area 1), individuals $\widetilde{N}^{r}, \widehat{N}^{p}$ and $\widetilde{N}^{p}$ still strictly prefer to live in urban area 2. This equilibrium is stable.

Case 2. When $\widehat{N}_{t}^{r}<L$, we have to consider three cases.

2.a) $R\left(w_{r}, \widetilde{h}, \rho_{t}, B_{t}\right)>R\left(w_{p}, \widehat{h}, \rho_{t}, B_{t}\right)$ for all $\rho_{t}$ and $B_{t}$. We construct a urban configuration such that rich individuals whatever their beliefs live in an area which is at least better as the one inhabited by the poor individuals. (i) If $\widehat{N}_{t}^{r} \geq B_{t} / 2$, and given that $R\left(w_{r}, \widetilde{h}, \rho_{t}, B_{t}\right)>R\left(w_{p}, \widehat{h}, \rho_{t}, B_{t}\right)$ for all $\rho_{t}$ and $B_{t}$ then it is possible that urban area is inhabited only by rich individuals such that $b_{t}^{1}=\widehat{N}_{t}^{r} / L>b_{t}^{2}$. Given that, for all $\rho_{t}$ and $B_{t}, R\left(w_{z}, \widehat{h}, \rho_{t}, B_{t}\right)>R\left(w_{z}, \widetilde{h}, \rho_{t}, B_{t}\right)$ for $z=r, p$ and that $R\left(w_{r}, \widetilde{h}, \rho_{t}, B_{t}\right)>R\left(w_{p}, \widehat{h}, \rho_{t}, B_{t}\right)$, with $\rho_{t}=\widetilde{\rho}^{r}\left(\widehat{N}_{t}^{r} / L\right)$ we have:

$$
\begin{aligned}
& u\left(w_{r}\right)-u\left(w_{r}-\widetilde{\rho}^{r}\left(\frac{\widehat{N}_{t}^{r}}{L}\right)\right)<a\left(\frac{2\left(\widehat{N}_{t}^{r} / L\right)-\left(B_{t} / L\right)}{c}\right)(2 \widehat{h})\left(\Delta w+\Delta u+2 \widehat{h} \frac{B_{t}}{L}-\frac{c}{2}\right) \\
& u\left(w_{r}\right)-u\left(w_{r}-\widetilde{\rho}^{r}\left(\frac{\widehat{N}_{t}^{r}}{L}\right)\right)=a\left(\frac{2\left(\widehat{N}_{t}^{r} / L\right)-\left(B_{t} / L\right)}{c}\right)(2 \widetilde{h})\left(\Delta w+\Delta u-2 \widetilde{h}\left(2-\frac{B_{t}}{L}\right)-\frac{c}{2}\right) \\
& u\left(w_{p}\right)-u\left(w_{p}-\widehat{\rho}^{r}\left(\frac{\widehat{N}_{t}^{r}}{L}\right)\right)>a\left(\frac{2\left(\widehat{N}_{t}^{r} / L\right)-\left(B_{t} / L\right)}{c}\right)(2 \widehat{h})\left(\Delta w+\Delta u+2 \widehat{h} \frac{B_{t}}{L}-\frac{c}{2}\right) \\
& u\left(w_{p}\right)-u\left(w_{p}-\widehat{\rho}^{r}\left(\frac{\widehat{N}_{t}^{r}}{L}\right)\right)>a\left(\frac{2\left(\widehat{N}_{t}^{r} / L\right)-\left(B_{t} / L\right)}{c}\right)(2 \widetilde{h})\left(\Delta w+\Delta u-2 \widetilde{h}\left(2-\frac{B_{t}}{L}\right)-\frac{c}{2}\right) .
\end{aligned}
$$

Hence, nobody has an incentive to move. The duple $\left[\widetilde{\rho}^{r}\left(\widehat{N}_{t}^{r} / L\right), b_{t}^{1}=\widehat{N}_{t}^{r} / L\right]$ is thus an equilibrium. Whatever the small perturbation of the area 1 population, individuals $\widehat{N}_{t}^{r}$, respectively $\widehat{N}^{p}$ and $\widetilde{N}^{p}$, still strictly prefer to live in urban area 1 , respectively urban area 2 . This equilibrium is stable. If $\widehat{N}_{t}^{r}<B_{t} / 2$, it would not be possible that urban area 1 inhabited only by rich individuals would be such that $b_{t}^{1}>b_{t}^{2}$. (ii) If $L-\widetilde{N}_{t}^{r}>B_{t} / 2$ and $\widetilde{N}_{t}^{r}+\widehat{N}_{t}^{r}<L$, and given that $R\left(w_{r}, \widetilde{h}, \rho_{t}, B_{t}\right)>$ $R\left(w_{p}, \widehat{h}, \rho_{t}, B_{t}\right)$ for all $\rho$ and $B_{t}$ then it is possible that urban area is inhabited by the whole rich population and a fraction of the $\widehat{N}_{t}^{p}$ population such that $b_{t}^{1}=\frac{L-\widetilde{N}_{t}^{r}}{L}>b_{t}^{2}$. Given that, for any $\rho_{t}$ and $B_{t}, R\left(w_{z}, \widehat{h}, \rho_{t}, B_{t}\right)>R\left(w_{z}, \widetilde{h}, \rho_{t}, B_{t}\right)$ for $z=r, p$, and that $R\left(w_{r}, \widetilde{h}, \rho_{t}, B_{t}\right)>R\left(w_{p}, \widehat{h}, \rho_{t}, B_{t}\right)$, 
we have:

$$
\begin{aligned}
& u\left(w_{r}\right)-u\left(w_{r}-\widehat{\rho}^{p}\left(\frac{L-\widetilde{N}_{t}^{r}}{L}\right)\right)<a\left(\frac{2\left(L-\widetilde{N}_{t}^{r}\right) / L-\left(B_{t} / L\right)}{c}\right)(2 \widehat{h})\left(\Delta w+\Delta u+2 \widehat{h} \frac{B_{t}}{L}-\frac{c}{2}\right) \\
& u\left(w_{r}\right)-u\left(w_{r}-\widehat{\rho}^{p}\left(\frac{L-\widetilde{N}_{t}^{r}}{L}\right)\right)<a\left(\frac{2\left(L-\widetilde{N}_{t}^{r}\right) / L-\left(B_{t} / L\right)}{c}\right)(2 \widetilde{h})\left(\Delta w+\Delta u-2 \widetilde{h}\left(2-\frac{B_{t}}{L}\right)-\frac{c}{2}\right) \\
& u\left(w_{p}\right)-u\left(w_{p}-\widehat{\rho}^{p}\left(\frac{L-\widetilde{N}_{t}^{r}}{L}\right)\right)=a\left(\frac{2\left(L-\widetilde{N}_{t}^{r}\right) / L-\left(B_{t} / L\right)}{c}\right)(2 \widehat{h})\left(\Delta w+\Delta u+2 \widehat{h} \frac{B_{t}}{L}-\frac{c}{2}\right) \\
& u\left(w_{p}\right)-u\left(w_{p}-\widehat{\rho}^{p}\left(\frac{L-\widetilde{N}_{t}^{r}}{L}\right)\right)>a\left(\frac{2\left(L-\widetilde{N}_{t}^{r}\right) / L-\left(B_{t} / L\right)}{c}\right)(2 \widetilde{h})\left(\Delta w+\Delta u-2 \widetilde{h}\left(2-\frac{B_{t}}{L}\right)-\frac{c}{2}\right) .
\end{aligned}
$$

No one has an incentive to move. The duple $\left[\widehat{\rho}^{p}\left(\left(L-\widetilde{N}_{t}^{r}\right) / L\right), b_{t}^{1}=\left(L-\widetilde{N}_{t}^{r}\right) / L\right]$ is thus an equilibrium. Whatever the small perturbation of the area 1 population, individuals $\widehat{N}_{t}^{r}$ and $\widetilde{N}_{t}^{r}$, respectively $\widetilde{N}_{t}^{p}$ still strictly prefer to live in urban area 1 , respectively 2 . This equilibrium is stable. (iii) If $\widetilde{N}_{t}^{p}>L$, given that, for any $\rho_{t}$ and $B_{t}, R\left(w_{z}, \widehat{h}, \rho_{t}, B_{t}\right)>R\left(w_{z}, \widetilde{h}, \rho_{t}, B_{t}\right)$ for $z=r, p$ and that $R\left(w_{r}, \widetilde{h}, \rho_{t}, B_{t}\right)>R\left(w_{p}, \widehat{h}, \rho_{t}, B_{t}\right)$ then, if urban area 1 is inhabited by the whole believer population, that is $b_{t}^{1}=B_{t} / L$, we have

$$
\begin{aligned}
& u\left(w_{r}\right)-u\left(w_{r}-\widetilde{\rho}^{p}\left(\frac{B_{t}}{L}\right)\right)<a\left(\frac{B_{t} / L}{c}\right)(2 \widehat{h})\left(\Delta w+\Delta u+2 \widehat{h} \frac{B_{t}}{L}-\frac{c}{2}\right) \\
& u\left(w_{r}\right)-u\left(w_{r}-\widetilde{\rho}^{p}(1)\right)<a\left(\frac{B_{t} / L}{c}\right)(2 \widetilde{h})\left(\Delta w+\Delta u-2 \widetilde{h}\left(2-\frac{B_{t}}{L}\right)-\frac{c}{2}\right) \\
& u\left(w_{p}\right)-u\left(w_{p}-\widetilde{\rho}^{p}(1)\right)<a\left(\frac{B_{t} / L}{c}\right)(2 \widehat{h})\left(\Delta w+\Delta u+2 \widehat{h} \frac{B_{t}}{L}-\frac{c}{2}\right) \\
& u\left(w_{p}\right)-u\left(w_{p}-\widetilde{\rho}^{p}(1)\right)=a\left(\frac{B_{t} / L}{c}\right)(2 \widetilde{h})\left(\Delta w+\Delta u-2 \widetilde{h}\left(2-\frac{B_{t}}{L}\right)-\frac{c}{2}\right) .
\end{aligned}
$$

No one has an incentive to move. The duple $\left[\widetilde{\rho}^{p}\left(B_{t} / L\right), b_{t}^{1}=B_{t} / L\right]$ is thus an equilibrium. After a small reduction of the number of believers in area 1, individuals $\widehat{N}_{t}^{r}, \widetilde{N}^{r}$ and $\widehat{N}^{p}$ still strictly prefer to live in urban area 1 . This equilibrium is stable.

Items (i), (ii) and (iii) cover the whole possible cases.

2.b) $R\left(w_{p}, \widehat{h}, \rho_{t}, B_{t}\right)>R\left(w_{r}, \widetilde{h}, \rho_{t}, B_{t}\right)$ for all $\rho_{t}$ and $B_{t}$. Poor believers are thus able to outbid rich non-believers to live in the better neighborhood. We thus construct urban configuration where all believers live in an area at least as good as the area inhabited by non-believers. (i) If $B_{t} \geq L$, given that, for any $\rho_{t}$ and $B_{t}, R\left(w_{z}, \widehat{h}, \rho_{t}, B_{t}\right)>R\left(w_{z}, \widetilde{h}, \rho_{t}, B_{t}\right)$ for $z=r, p$ and that $R\left(w_{p}, \widehat{h}, \rho_{t}, B_{t}\right)>R\left(w_{r}, \widetilde{h}, \rho_{t}, B_{t}\right)$, then if urban area 1 is inhabited by the whole believer 
population, that is $b_{t}^{1}=1$, we have:

$$
\begin{aligned}
& u\left(w_{r}\right)-u\left(w_{r}-\widehat{\rho}^{p}(1)\right)<a\left(\frac{2-\left(B_{t} / L\right)}{c}\right)(2 \widehat{h})\left(\Delta w+\Delta u+2 \widehat{h} \frac{B_{t}}{L}-\frac{c}{2}\right) \\
& u\left(w_{r}\right)-u\left(w_{r}-\widehat{\rho}^{p}(1)\right)>a\left(\frac{2-\left(B_{t} / L\right)}{c}\right)(2 \widetilde{h})\left(\Delta w+\Delta u-2 \widetilde{h}\left(2-\frac{B_{t}}{L}\right)-\frac{c}{2}\right) \\
& u\left(w_{p}\right)-u\left(w_{p}-\widehat{\rho}^{p}(1)\right)=a\left(\frac{2-\left(B_{t} / L\right)}{c}\right)(2 \widehat{h})\left(\Delta w+\Delta u+2 \widehat{h} \frac{B_{t}}{L}-\frac{c}{2}\right) \\
& u\left(w_{p}\right)-u\left(w_{p}-\widetilde{\rho}^{p}(1)\right)>a\left(\frac{2-\left(B_{t} / L\right)}{c}\right)(2 \widetilde{h})\left(\Delta w+\Delta u-2 \widetilde{h}\left(2-\frac{B_{t}}{L}\right)-\frac{c}{2}\right) .
\end{aligned}
$$

No one has an incentive to move. The duple $\left[\widehat{\rho}^{p}(1), b_{t}^{1}=1\right]$ is thus an equilibrium. After a small reduction of the number of believers in area 1, individuals $\widehat{N}_{t}^{r}$, respectively $\widetilde{N}^{r}$ and $\widetilde{N}^{p}$, still strictly prefer to live in urban area 1 , respectively 2 . This equilibrium is stable. (ii) If $B_{t}<L$ and $\widetilde{N}_{t}^{p}<L$, given that, for any $\rho_{t}$ and $B_{t}, R\left(w_{z}, \widehat{h}, \rho_{t}, B_{t}\right)>R\left(w_{z}, \widetilde{h}, \rho_{t}, B_{t}\right)$ for $z=r, p$ and that $R\left(w_{p}, \widehat{h}, \rho_{t}, B_{t}\right)>R\left(w_{r}, \widetilde{h}, \rho_{t}, B_{t}\right)$, then if urban area 1 is inhabited by the whole believer population, that is $b_{t}^{1}=B_{t} / L$, with $\rho=\widetilde{\rho}^{r}\left(B_{t} / L\right)$ we have:

$$
\begin{aligned}
& u\left(w_{r}\right)-u\left(w_{r}-\widetilde{\rho}^{r}\left(\frac{B_{t}}{L}\right)\right)<a\left(\frac{\left(B_{t} / L\right)}{c}\right)(2 \widehat{h})\left(\Delta w+\Delta u+2 \widehat{h} \frac{B_{t}}{L}-\frac{c}{2}\right) \\
& u\left(w_{r}\right)-u\left(w_{r}-\widetilde{\rho}^{r}\left(\frac{B_{t}}{L}\right)\right)=a\left(\frac{\left(B_{t} / L\right)}{c}\right)(2 \widetilde{h})\left(\Delta w+\Delta u-2 \widetilde{h}\left(2-\frac{B_{t}}{L}\right)-\frac{c}{2}\right) \\
& u\left(w_{p}\right)-u\left(w_{p}-\widetilde{\rho}^{r}\left(\frac{B_{t}}{L}\right)\right)<a\left(\frac{\left(B_{t} / L\right)}{c}\right)(2 \widehat{h})\left(\Delta w+\Delta u+2 \widehat{h} \frac{B_{t}}{L}-\frac{c}{2}\right) \\
& u\left(w_{p}\right)-u\left(w_{p}-\widetilde{\rho}^{r}\left(\frac{B_{t}}{L}\right)\right)>a\left(\frac{\left(B_{t} / L\right)}{c}\right)(2 \widetilde{h})\left(\Delta w+\Delta u-2 \widetilde{h}\left(2-\frac{B_{t}}{L}\right)-\frac{c}{2}\right) .
\end{aligned}
$$

No one has an incentive to move. The duple $\left[\widetilde{\rho}^{r}\left(B_{t} / L\right), b_{t}^{1}=B_{t} / L\right]$ is thus an equilibrium. After a small reduction of the number of believers in area 1, individuals $\widehat{N}_{t}^{r}$ and $\widehat{N}_{t}^{p}$, respectively $\widetilde{N}_{t}^{p}$, still strictly prefer to live in urban area 1 , respectively 2 . This equilibrium is stable. (iii) If $B_{t}<L$ and $\widetilde{N}_{t}^{p}>L$, given that, for any $\rho_{t}$ and $B_{t}, R\left(w_{z}, \widehat{h}, \rho_{t}, B_{t}\right)>R\left(w_{z}, \widetilde{h}, \rho_{t}, B_{t}\right)$ for $z=r, p$ and that $R\left(w_{p}, \widehat{h}, \rho_{t}, B_{t}\right)>R\left(w_{r}, \widetilde{h}, \rho_{t}, B_{t}\right)$, then if urban area 1 is inhabited by the whole believer population, that is $b_{t}^{1}=B_{t} / L$, with $\rho=\widetilde{\rho}^{p}\left(B_{t} / L\right)$ we have:

$$
\begin{aligned}
& u\left(w_{r}\right)-u\left(w_{r}-\widetilde{\rho}^{p}\left(\frac{B_{t}}{L}\right)\right)<a\left(\frac{B_{t} / L}{c}\right)(2 \widehat{h})\left(\Delta w+\Delta u+2 \widehat{h} \frac{B_{t}}{L}-\frac{c}{2}\right) \\
& u\left(w_{r}\right)-u\left(w_{r}-\widetilde{\rho}^{p}\left(\frac{B_{t}}{L}\right)\right)<a\left(\frac{B_{t} / L}{c}\right)(2 \widetilde{h})\left(\Delta w+\Delta u-2 \widetilde{h}\left(2-\frac{B_{t}}{L}\right)-\frac{c}{2}\right) \\
& u\left(w_{p}\right)-u\left(w_{p}-\widetilde{\rho}^{p}\left(\frac{B_{t}}{L}\right)\right)<a\left(\frac{B_{t} / L}{c}\right)(2 \widehat{h})\left(\Delta w+\Delta u+2 \widehat{h} \frac{B_{t}}{L}-\frac{c}{2}\right) \\
& u\left(w_{p}\right)-u\left(w_{p}-\widetilde{\rho}^{p}\left(\frac{B_{t}}{L}\right)\right)=a\left(\frac{B_{t} / L}{c}\right)(2 \widetilde{h})\left(\Delta w+\Delta u-2 \widetilde{h}\left(2-\frac{B_{t}}{L}\right)-\frac{c}{2}\right) .
\end{aligned}
$$


No one has an incentive to move. The duple $\left[\widetilde{\rho}^{p}\left(B_{t} / L\right), b_{t}^{1}=B_{t} / L\right]$ is thus an equilibrium. After a small reduction of the number of believers in area 1, individuals $\widehat{N}_{t}^{r}, \widehat{N}_{t}^{p}$ and $\widetilde{N}_{t}^{r}$ still strictly prefer to live in urban area 1 . This equilibrium is stable.

2.c) Let us now consider that indifference curves may cross more than once. If for some $b_{t} \in\left[B_{t} / 2 L, 1\right]$, we have $\rho$ such that

$$
\begin{aligned}
& u\left(w_{r}\right)-u\left(w_{r}-\rho\right)<a\left(\frac{2 b_{t}-\left(B_{t} / L\right)}{c}\right)(2 \widehat{h})\left(\Delta w+\Delta u+2 \widehat{h} \frac{B_{t}}{L}-\frac{c}{2}\right) \\
& u\left(w_{r}\right)-u\left(w_{r}-\rho\right)=a\left(\frac{2 b_{t}-\left(B_{t} / L\right)}{c}\right)(2 \widetilde{h})\left(\Delta w+\Delta u-2 \widetilde{h}\left(2-\frac{B_{t}}{L}\right)-\frac{c}{2}\right) \\
& u\left(w_{p}\right)-u\left(w_{p}-\rho\right)=a\left(\frac{2 b_{t}-\left(B_{t} / L\right)}{c}\right)(2 \widehat{h})\left(\Delta w+\Delta u+2 \widehat{h} \frac{B_{t}}{L}-\frac{c}{2}\right) \\
& u\left(w_{p}\right)-u\left(w_{p}-\rho\right)>a\left(\frac{2-\left(B_{t} / L\right)}{c}\right)(2 \widetilde{h})\left(\Delta w+\Delta u-2 \widetilde{h}\left(2-\frac{B_{t}}{L}\right)-\frac{c}{2}\right)
\end{aligned}
$$

then $\left[\rho=\widetilde{\rho}^{r}\left(b_{t}\right)=\widehat{\rho}^{p}\left(b_{t}\right), b_{t}^{1}=b_{t}\right]$ is an equilibrium as no one has an incentive to move. Let us consider a move of $\varepsilon$ individuals $\widehat{N}^{p}$ from area 2 in area 1 and a reverse move of individuals $\widetilde{N}^{r}$. If and only if $R\left(w_{r}, \widetilde{h}, \rho, B_{t}\right)-R\left(w_{p}, \widehat{h}, \rho, B_{t}\right)>0$, individuals $\widetilde{N}^{r}$ who have been jarred out from area 1 are able to outbid individuals $\widehat{N}^{p}$ to live in area 1 .

Let us now consider Proposition 8.

Case 1. If $R\left(w_{r}, \widehat{h}, \rho_{t}, B_{t}\right)<R\left(w_{p}, \widetilde{h}, \rho_{t}, B_{t}\right)$ for all $\rho_{t}, B_{t}$, non-believers individuals are able to outbid believers to live in a better neighborhood. Given that, for all $\rho_{t}, B_{t}, R\left(w_{r}, \widehat{h}, \rho_{t}, B_{t}\right)<$ $R\left(w_{p}, \widetilde{h}, \rho_{t}, B_{t}\right)$ and $R\left(w_{z}, \widehat{h}, \rho_{t}, B_{t}\right)<R\left(w_{z}, \widetilde{h}, \rho_{t}, B_{t}\right)$ for $z=r, p$, it is thus impossible to have an equilibrium with $b_{t}^{1}>b_{t}^{2}$ as all non-believers living in area 2 would have an incentive to move in area 1 and can outbid its believers inhabitants.

Case 2. If $R\left(w_{r}, \widehat{h}, \rho_{t}, B_{t}\right)>R\left(w_{p}, \widetilde{h}, \rho_{t}, B_{t}\right)$ for all $\rho_{t}, B_{t}$, rich believers are able to outbid poor non-believers. Given that, for all $\rho_{t}, B_{t}, R\left(w_{r}, \widehat{h}, \rho_{t}, B_{t}\right)>R\left(w_{p}, \widetilde{h}, \rho_{t}, B_{t}\right)$ and $R\left(w_{z}, \widehat{h}, \rho_{t}, B_{t}\right)<$ $R\left(w_{z}, \widetilde{h}, \rho_{t}, B_{t}\right)$ for $z=r, p$, we can build an equilibrium with $b_{t}^{1}>b_{t}^{2}$. Two cases must be considered. (i) When $\widehat{N}_{t}^{r}>B_{t} / 2$ and $L-\widetilde{N}_{t}^{r}=\widehat{N}_{t}^{r, 1}>B_{t} / 2$, given that, for all $\rho_{t}, B_{t}$, $R\left(w_{z}, \widehat{h}, \rho_{t}, B_{t}\right)<R\left(w_{z}, \widetilde{h}, \rho_{t}, B_{t}\right)$ for $z=r, p$ and that $R\left(w_{r}, \widehat{h}, \rho_{t}, B_{t}\right)>R\left(w_{p}, \widetilde{h}, \rho_{t}, B_{t}\right)$, then if urban area 1 is inhabited by the whole rich non-believers population and a number $\widehat{N}_{t}^{r, 1}$ of rich 
believers, that is $b_{t}^{1}=\widehat{N}_{t}^{r, 1} / L$, with $\rho=\widehat{\rho}^{r}\left(\widehat{N}_{t}^{r, 1} / L\right)$ we have:

$$
\begin{aligned}
& u\left(w_{r}\right)-u\left(w_{r}-\widehat{\rho}^{r}\left(\frac{\widehat{N}_{t}^{r, 1}}{L}\right)\right)<a\left(\frac{2 \widehat{N}_{t}^{r, 1} / L-\left(B_{t} / L\right)}{c}\right)(2 \widetilde{h})\left(\Delta w+\Delta u-2 \widetilde{h}\left(2-\frac{B_{t}}{L}\right)-\frac{c}{2}\right) \\
& u\left(w_{r}\right)-u\left(w_{r}-\widehat{\rho}^{r}\left(\frac{\widehat{N}_{t}^{r, 1}}{L}\right)\right)=a\left(\frac{2 \widehat{N}_{t}^{r, 1} / L-\left(B_{t} / L\right)}{c}\right)(2 \widehat{h})\left(\Delta w+\Delta u+2 \widehat{h} \frac{B_{t}}{L}-\frac{c}{2}\right) \\
& u\left(w_{p}\right)-u\left(w_{p}-\widehat{\rho}^{r}\left(\frac{\widehat{N}_{t}^{r, 1}}{L}\right)\right)>a\left(\frac{2 \widehat{N}_{t}^{r, 1} / L-\left(B_{t} / L\right)}{c}\right)(2 \widetilde{h})\left(\Delta w+\Delta u-2 \widetilde{h}\left(2-\frac{B_{t}}{L}\right)-\frac{c}{2}\right) \\
& u\left(w_{p}\right)-u\left(w_{p}-\widehat{\rho}^{r}\left(\frac{\widehat{N}_{t}^{r, 1}}{L}\right)\right)>a\left(\frac{2 \widehat{N}_{t}^{r, 1} / L-\left(B_{t} / L\right)}{c}\right)(2 \widehat{h})\left(\Delta w+\Delta u+2 \widehat{h} \frac{B_{t}}{L}-\frac{c}{2}\right) .
\end{aligned}
$$

The duple $\left[\widehat{\rho}^{r}\left(\widehat{N}_{t}^{r, 1} / L\right), b_{t}^{1}=\widehat{N}_{t}^{r, 1} / L\right]$ is an equilibrium as nobody has an incentive to move. Further, whatever the small perturbation of the equilibrium, individuals $\widetilde{N}_{t}^{r}$, respectively $\widehat{N}_{t}^{p}$ and $\widetilde{N}_{t}^{p}$, still strictly prefer to live in urban area 1 , respectively 2 . This equilibrium is stable.

(ii) When $\widehat{N}_{t}^{r}>B_{t} / 2, \widetilde{N}_{t}^{r}+\widehat{N}_{t}^{r}<L$ and $\widetilde{N}_{t}^{r}+\widehat{N}_{t}^{r}+\widetilde{N}_{t}^{p}>L$, given that, for all $\rho_{t}, B_{t}$, $R\left(w_{z}, \widehat{h}, \rho_{t}, B_{t}\right)<R\left(w_{z}, \widetilde{h}, \rho_{t}, B_{t}\right)$ for $z=r, p$ and that $R\left(w_{r}, \widehat{h}, \rho_{t}, B_{t}\right)>R\left(w_{p}, \widetilde{h}, \rho_{t}, B_{t}\right)$ then if urban area 1 is inhabited by the whole rich population, $b_{t}^{1}=\widehat{N}_{t}^{r} / L$ and $\rho=\widetilde{\rho}^{p}\left(\widehat{N}_{t}^{r} / L\right)$ we have:

$$
\begin{aligned}
& u\left(w_{r}\right)-u\left(w_{r}-\widetilde{\rho}^{p}\left(\frac{\widehat{N}_{t}^{r}}{L}\right)\right)<a\left(\frac{2 \widehat{N}_{t}^{r} / L-\left(B_{t} / L\right)}{c}\right)(2 \widetilde{h})\left(\Delta w+\Delta u-2 \widetilde{h}\left(2-\frac{B_{t}}{L}\right)-\frac{c}{2}\right) \\
& u\left(w_{r}\right)-u\left(w_{r}-\widetilde{\rho}^{p}\left(\frac{\widehat{N}_{t}^{r}}{L}\right)\right)<a\left(\frac{2 \widehat{N}_{t}^{r} / L-\left(B_{t} / L\right)}{c}\right)(2 \widehat{h})\left(\Delta w+\Delta u+2 \widehat{h} \frac{B_{t}}{L}-\frac{c}{2}\right) \\
& u\left(w_{p}\right)-u\left(w_{p}-\widetilde{\rho}^{p}\left(\frac{\widehat{N}_{t}^{r}}{L}\right)\right)=a\left(\frac{2 \widehat{N}_{t}^{r} / L-\left(B_{t} / L\right)}{c}\right)(2 \widetilde{h})\left(\Delta w+\Delta u-2 \widetilde{h}\left(2-\frac{B_{t}}{L}\right)-\frac{c}{2}\right) \\
& u\left(w_{p}\right)-u\left(w_{p}-\widetilde{\rho}^{p}\left(\frac{\widehat{N}_{t}^{r}}{L}\right)\right)>a\left(\frac{2 \widehat{N}_{t}^{r} / L-\left(B_{t} / L\right)}{c}\right)(2 \widehat{h})\left(\Delta w+\Delta u+2 \widehat{h} \frac{B_{t}}{L}-\frac{c}{2}\right) .
\end{aligned}
$$

The duple $\left[\widetilde{\rho}^{p}\left(\widehat{N}_{t}^{r} / L\right), b_{t}^{1}=\widehat{N}_{t}^{r} / L\right]$ is an equilibrium as no body has an incentive to move. Further, whatever the small perturbation of the equilibrium, individuals $\widetilde{N}_{t}^{r}, \widehat{N}_{t}^{r}$, respectively $\widetilde{N}_{t}^{p}$, still strictly prefer to live in urban area 1 , respectively 2 . This equilibrium is stable.

When $\widehat{N}_{t}^{r}>B_{t} / 2, \widetilde{N}_{t}^{r}+\widehat{N}_{t}^{r}<L$ and $\widetilde{N}_{t}^{r}+\widehat{N}_{t}^{r}+\widetilde{N}_{t}^{p}<L$, given that, for all $\rho_{t}, B_{t}$, $R\left(w_{z}, \widehat{h}, \rho_{t}, B_{t}\right)<R\left(w_{z}, \widetilde{h}, \rho_{t}, B_{t}\right)$ for $z=r, p$ and that $R\left(w_{r}, \widehat{h}, \rho_{t}, B_{t}\right)>R\left(w_{p}, \widetilde{h}, \rho_{t}, B_{t}\right)$, it is impossible to have an equilibrium such that $b_{t}^{1}>b_{t}^{2}$ as area 2 would be inhabited by poor believers, i.e. $b_{t}^{2}=1$.

Finally, we provide a numerical example to prove item (iii) of Proposition 5. Let us assume that the instantaneous utility function is $u(x)=-x^{2}+2 x+1$. It is increasing for $0<x<1$ and strictly 
concave. We have multiple equilibria if and only if the following equations are simultaneously satisfied for different values of $b_{t}^{1}$

$$
\begin{aligned}
\frac{u\left(w_{r}\right)-u\left(w_{r}-\rho\right)}{2 \widetilde{h}\left(\Delta w+\Delta u-2 \widetilde{h}\left(2-\frac{B}{L}\right)-\frac{c}{2}\right)} & =a\left(\frac{2 b_{t}^{1}-\frac{B_{t}}{L}}{c}\right) \\
\frac{u\left(w_{r}\right)-u\left(w_{r}-\rho\right)}{2 \widetilde{h}\left(\Delta w+\Delta u-2 \widetilde{h}\left(2-\frac{B}{L}\right)-\frac{c}{2}\right)} & =\frac{u\left(w_{p}\right)-u\left(w_{p}-\rho\right)}{2 \widehat{h}\left(\Delta w+\Delta u+2 \widehat{h} \frac{B}{L}-\frac{c}{2}\right)} .
\end{aligned}
$$

Parameters are supposed to take the following values $w_{r}=0.98, w_{p}=0.34, \Delta w=0.64, c=0.75$, $\widetilde{h}=0.22, \widehat{h}=0.45$ and $a=0.8$. Consider that $B_{t} / L=1.5$. We have $\Delta u \equiv u\left(w_{r}\right)-u\left(w_{p}\right)=$ 0.4352. Note that these values satisfy both assumptions 2 and 3. Assumption 2 (i) $\Delta u / c=$ $0.4352 / 0.75<1$, (ii) $(c-\Delta u) / 2 \widehat{h}=(0.75-0.4352) / 0.9<1$, (iii) $\Delta u / 2 \widetilde{h}=0.98909<1$. Assumption $3(c-\Delta u) / 2 \widehat{h}=0.34978>1-\Delta u / 2 \widetilde{h}=0.01091$.

There exist three urban equilibria:

\begin{tabular}{||c||c||c||c||}
\hline \hline & $\rho$ & $b_{t}^{1}$ & Stability \\
\hline \hline Culturally-Balanced City & 0 & $\frac{B_{t}}{2 L}=0.75$ & yes \\
\hline \hline Culturally-Divided City & 0.14958 & 0.81291 & no \\
\hline \hline Culturally-Divided City & $\rho=\left\{\begin{array}{c}\widehat{\rho}^{p}(1) \text { if } \widehat{N}^{r}<L \\
\widehat{\rho}^{r}(1) \text { otherwise. }\end{array}\right.$ & 1 & yes \\
\hline \hline
\end{tabular}

We can compute that both duples $\left(\rho=0, b_{t}^{1}=B_{t} / 2 L=0.2475\right)$ and $\left(\rho=0.14958, b_{t}^{1}=\right.$ 0.81291) are solutions of (20)-(21). Moreover, according to (17) and (18) and Definition 2, the culturally-balanced city is stable, i.e. $R\left(w_{r}, \widetilde{h}, 0,0.75\right)=2.4687>R\left(w_{p}, \widehat{h}, 0,0.75\right)=2.4367$. The culturally-divided city $\left(\rho=0.14958, b_{t}^{1}=0.81291\right)$ is unstable as $R\left(w_{r}, \widetilde{h}, 0.14958,1.5\right)=1.2598<$ $R\left(w_{p}, \widehat{h}, 0.14958,1.5\right)=2.4015$. The third equilibrium is a culturally-divided one with $b_{t}^{1}=1$ with the equilibrium rent equals to $\rho=\widehat{\rho}^{p}(1)=0.48416$ if $\widehat{N}^{r}<L$ and $\rho=\widehat{\rho}^{r}(1)=0.91483$ otherwise. It is stable as $\widehat{\rho}^{p}(1)=0.48416>\widetilde{\rho}^{r}(1)=0.31628$. 


\section{Highlights of "Dynamics of Social Norms in the City"}

- We study how in a city either opposite social norms remain or a particular code of behavior spreads and ultimately prevails.

- We develop a urban multicommunity model of norm diffusion.

- We identify multiple urban equilibria that arise at each date and are characterized by the mix of social norms in each urban area.

- The result that urban areas may differ with respect to the prevailing social norm helps to explain the observed spatial variation of social opportunities.

- The dynamics of social norms exhibit multiple history dependent steady states. 